
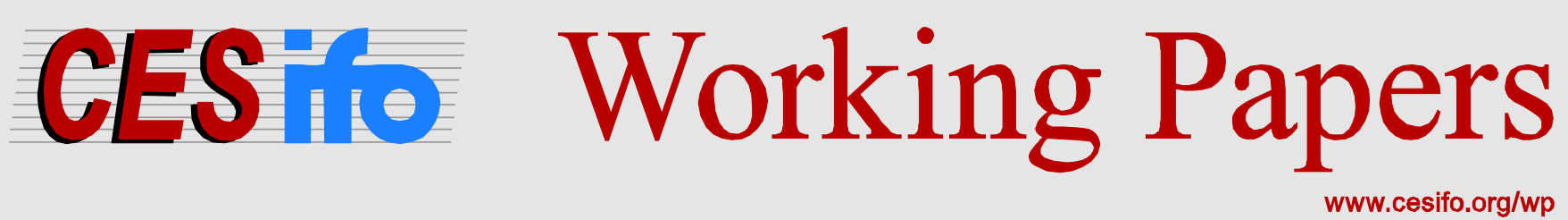

\title{
State Tax Differentials, Cross-Border Commuting, and Commuting Times in Multi-State Metropolitan Areas
}

\author{
David R. Agrawal \\ William H. Hoyt \\ CESIFO WORKING PAPER NO. 4852 \\ CATEgory 1: PuBliC FinANCE \\ JUNE 2014
An electronic version of the paper may be downloaded
- from the SSRN website:
- from the RePEc website:
WWW.SSRN.com
www.RePEc.org
www.CESifo-group.org/wp \\ - from the CESifo website:
}

\section{CESifo}




\title{
State Tax Differentials, Cross-Border Commuting, and Commuting Times in Multi-State Metropolitan Areas
}

\begin{abstract}
We examine the effects of differences in income tax rates on commuting times within multistate MSAs. Our theoretical model introduces a border into a model of an urban area and shows that differences in average tax rates distort commute times and interstate commutes. Empirically examining multi-state MSAs allows us to exploit tax policy discontinuities while holding fixed other characteristics. We identify large effects on commuting times for affluent households and homeowners in MSAs in which taxes are based on the state of residence. We discuss how the model and empirical design can be used to study other policy differences.
\end{abstract}

JEL-Code: H200, H710, H730, R120, R280, R410.

Keywords: tax differentials, transportation, inter-jurisdictional competition, commuting.

David R. Agrawal

University of Georgia

Department of Economics

527 Brooks Hall

USA - Athens, GA 30602

dagrawal@uga.edu
William H. Hoyt

University of Kentucky

Department of Economics

Gatton College of Business and Economics

USA - Lexington, KY 40506-0034

whoyt@uky.edu

This Version: June 2014

Thanks to David Albouy, Byron Lutz, Ronald Warren, Nicholas Sheard, Ian Schmutte, Gary Wagner, David Wildasin, and Jay Wilson for helpful comments and suggestions on previous versions of the paper. Conference and seminar participants at the University of Kentucky, the National Tax Association Meetings, the Southern Economic Association Meetings, and the Conference on Competition and Subnational Governments helped to improve the paper. Any remaining errors are our own. 
A large fraction of the United States population lives in metropolitan areas, with an even greater share of economic activity taking place in these urban areas. The economic benefits of urbanization are well-documented: improved economic mobility and opportunity, agglomeration and productivity gains, environmental benefits from density, and cultural and educational amenities. Not surprisingly, urbanization also comes with substantial costs. One of the most significant of these is the cost associated with work-related travel within metropolitan areas. In 2011, the average one-way commute in the U.S. was 25.5 minutes for all workers and 44.8 minutes for those workers commuting between states. Over eight percent of workers have one-way commutes of over one hour. The United States is not unique in this respect - average commute times are longer in South Korea, Japan, Latvia, and Mexico. In most European countries, commutes exceed twenty minutes in length as well. With the value of time (VOT) associated with commuting estimated to be in the range of $\$ 20.00$ to $\$ 40.00$ an hour (Brownstone and Small 2005), commuting entails substantial costs. The Texas A\&M Transportation Institute estimates that the cost of externalities from highway congestion is $\$ 818$ per commuter. Congestion adds 5.5 billion hours to commute times and 2.9 billion gallons in gasoline purchases. ${ }^{1}$

Can governments affect commute times and patterns? Glaeser and Kahn (2004) argue that government policies, including "bad" urban planning, play a limited role in generating urban sprawl. However, Baum-Snow (2007) and Baum-Snow (2010) find evidence that the development of the interstate highway system increased suburban populations at the expense of populations in central cities. Additionally, these studies show employment has become more decentralized as well, meaning that fewer suburban residents commute to the central city. In addition to these studies examining infrastructure, a small theoretical literature examines the impact of tax policies on the spatial structures of cities (metropolitan areas). Wildasin (1985), Brueckner and Kim (2003), and Voith and Gyourko (2002) show that increases in marginal income tax rates (which change the opportunity cost of time), property tax rates, and the mortgage interest deduction might lead to an expansion of the city. ${ }^{2}$ While these studies show how tax policies can change the spatial structure of a city, they assume uniform tax policies within the metropolitan area, ignoring the preponderance of heterogeneity across local and state tax policies within metropolitan areas.

Our interest is not in the impact of uniform government policies on sprawl and commuting costs, but rather, on the effect of policy discontinuities resulting from multiple jurisdictions

\footnotetext{
${ }^{1}$ The sources of these estimates are McKenzie (2013), OECD (2014), and Schrank, Eisele and Lomaz (2012).

${ }^{2}$ Distortions to city sizes and shapes also result from the transportation network (Anas and Moses 1979). Tax competition may also affect the equilibrium commuting flow (Gerritse 2013) and house prices (de Bartolome and Ross 2003).
} 
and multiple levels of government within metropolitan areas. Metropolitan areas in the United States are composed of multiple municipalities, counties, and school districts, and, for some of the largest MSAs, multiple states. Each of these multiple jurisdictions may provide distinct levels of public services that allow residents to sort into communities matching their preferences (Tiebout 1956), but policy differences or discontinues may result in sorting that leads to spatial mismatch of jobs and increased commuting costs. We focus on metropolitan areas that cross state borders and have different state income tax policies. Because 75 million people in the United States reside and work in multiple-state MSAs, understanding of the effect of policy discontinuities arising in these areas is important in its own right.

Using a novel model of an MSA split by a state border, we study the impact of state income tax differences on the city's shape and the location of employment and households. Critical to our predictions is whether states have reciprocity agreements: when taxes are based on the state of residence of the household, states are said to have reciprocity agreements; when taxes are paid based on the state of employment, no reciprocity agreements exist. We show that in multi-state MSAs with reciprocity agreements, the side of the MSA in the state with the higher average tax rate will be smaller in area and population, while the side in the state with the lower average tax rate will encompass a larger area and will have fewer people, ceteris paribus. Low-tax states will have more interstate commutes and, under reasonable assumptions, longer commutes. Intuitively, when taxes are based on residence, households relocate within the urban area. ${ }^{3}$ In MSAs where states do not have reciprocity agreements, tax differentials will not lead to differences in area or population, but employment will be lower on the high-tax side of the border; interstate commutes from the low-tax to high-tax state will be greater in number, and commute times will be longer. Intuitively, when taxes are based on the location of employment, businesses relocate. These distortions to commutes resulting from movements of households and businesses are inefficient. By introducing a border into a model of an MSA, our model will also be applicable to studying other policy discontinuities (educational, labor regulations, spending, etc.) across jurisdictions within the MSA.

We test these theoretical predictions empirically using household level Census data and tax rates generated using TAXSIM. Our empirical contribution is to identify the effect of taxes on commuting by exploiting the discontinuous change in the tax system at geographic borders along with the different effects in reciprocity and no reciprocity states. ${ }^{4}$ For a sample of households living in urban areas that cross state borders, we calculate marginal and average

\footnotetext{
${ }^{3}$ Migration across state borders is the subject of Young and Varner (2011).

${ }^{4}$ Exploiting discontinuous changes (or notches) in the tax system to achieve causal identification is a recent topic within public economics. Exploiting policy differentials at borders was pioneered by Holmes (1998).
} 
tax rates in the state of residence for these households and we construct the counter-factual tax rate that the households would have faced had they lived in the other state in the MSA, all else equal. The identification strategy exploits the fact that both sides of the MSA share a common labor market, which allows us to determine the counter-factual tax rate. As our theory suggests, we find smaller effects in MSAs with no reciprocity agreements, but find economically large and statistically significant effects in MSAs with agreements. Among low-income households, the response to tax differentials is relatively small, but the the effect on commute times increases substantially with income, a finding that is consistent with these households having larger absolute tax differentials. For households earning more than $\$ 500,000$, a one percentage point change in the tax differential between the states in the MSA can affect commute times by up to 2 minutes per trip which is 8 percent of the average commute. At $\$ 30$ an hour, the monetary value of this change in commute times is $\$ 540$ per year; using an hourly wage more appropriate for these households yields estimates over $\$ 2000$ a year, which is approximately $40 \%$ of the tax payment. While our results suggest that differences in income taxes have little effect on commute times for renters, we find that statistically and economically significant effects for homeowners across the income distribution.

To summarize the point of our paper, cities are decentralized and composed of multiple jurisdictions; this aspect is not addressed by models of the monocentric city. ${ }^{5}$ Our paper provides a framework for studying the effects of decentralization and jurisdictional borders within cities. This decentralization sometimes results in an inefficient spatial structure of the MSA. To better understand the dynamics of these cities, we introduce geographic borders that allow for policies, regulations, and spending to vary not only across cities, but within cities.

\section{Theory: Multi-State Urban Areas}

We begin by considering a model of a closed metropolitan area (MSA) or city that is located in two states $(i=1,2)$. The MSA has a fixed population of $N$ identical individuals, with $N^{i}$ individuals residing in each state. We assume a linear city with one unit of land at each location with the terminus (boundary) of state $i$ denoted by $r_{T}^{i}{ }^{6}$ Each individual provides a single unit of labor. Employment is found in the Central Business District (CBD) of each of the two states. The boundaries of the CBDs are fixed, and in fact, the CBD is a mass point. But, the allocation of employment between the two states is endogenously determined and

\footnotetext{
${ }^{5}$ For issues on decentralization, see Calabrese, Epple and Romano (2012) and Calabrese, Cassidy and Epple (2002).

${ }^{6}$ The monocentric city model originates with Alonso (1964), Muth (1969), and Mills (1972).
} 
how much of it is in each state depends on the states' tax policies. ${ }^{7}$ We let $r$ denote the distance an individual lives from the edge of the CBD in that state. Individuals commute to work at a cost of $c$ per unit of distance. Then, for an individual living at $r$ and commuting to the CBD in the state of her residence, total commuting costs are $\mathrm{cr}$. If the individual commutes to the CBD of the other state, there is an additional cost of $S$ associated with an interstate commute making the total cost of the commute equal to $\mathrm{cr}+S .{ }^{8}$ Individuals face no costs associated with moving from one state to the other in the MSA.

Production in state $i$ is given by the function $f_{i}\left(E_{i}\right), i=1,2$, where $E_{i}$ is the employment in state $i$. We assume that $f_{i}^{\prime}>0$, and $f_{i} "<0, i=1,2$ that is, production in each state exhibits positive but diminishing marginal product. The marginal product of labor depends on the employment in the state and decreases as employment increases in that state's part of the CBD. This can be thought of as a reduction in productivity due to congestion and negative spillovers. ${ }^{9}$

Individual utility is defined over the private good $(x)$ and land $(l)$ by the quasilinear utility function $U=x+m(l), m^{\prime}>0, m^{\prime \prime}<0$. Then, the indirect utility function is simply $V^{i}\left(T^{i}, r\right)=w^{j}-c r-T^{i}-p^{i}(r) l\left(p^{i}(r)\right)+m\left(l\left(p^{i}(r)\right)\right.$ where $p^{i}(r)$ is the price of land at distance $r, w^{j}$ is the wage rate where $j$ is the state of employment, and the price of $x$ is normalized to one. For an individual residing in state $i$ at distance $r$ the demand for land is given by $l\left(p^{i}(r)\right)$. $T^{k}$ is a lump-sum tax assessed to each individual where $k$ is the state of residence when there are reciprocity agreements and $k$ is the state of employment when there are no reciprocity agreements. ${ }^{10}$ At the termini land rent is equal to $p^{*}$, the rent on the alternative use (agriculture). As we have normalized land at any distance $r$ to be one unit, the population at distance $r$ in state $i$ is simply $N^{i}(r)=\frac{1}{l^{i}(r)}$.

\subsection{Equilibrium Conditions}

\footnotetext{
${ }^{7}$ We can allow the CBD to take on an exogenous amount of area in each state and the results remain unchanged. This simply changes the bounds of integration in the formulas, so we think of the mass point $\mathrm{CBD}$ as a normalization. In addition, we can make the boundaries of the CBD endogenous. Under similar assumptions on the parameters, the results maintain their spirit.

${ }^{8}$ For a given $r$, an interstate commute is always more costly than a commute to the state of residence. Thus, $S$ captures the additional distance to travel to the other state's CBD or may be thought of as the cost of crossing a river.

${ }^{9}$ Of course, this is not to disregard the possibility of agglomeration economies. However, as this model is closed with a fixed level of employment, those agglomerations are likely to be at the MSA rather than the state level and, therefore, are not captured in our analysis.

${ }^{10}$ Note that we have not specified any use for the tax revenue. We assume that it either leaves the MSA, that is, it is not received by residents in the MSA nor is it used to provide services to MSA residents. Alternatively, the revenues could be distributed equally to residents of the MSA. We discuss the implications of having the tax revenue used to finance a public service in section 1.5. An advantage of the quasi-linear utility function is that the demand for land is independent of income.
} 
We describe the equilibrium conditions for a city in which individuals live and work in both states. While we assume all residents of state 1 work in state 1 , without loss of generality, we also assume that residents of state 2 living between the central business district $(r=0)$ until point $\widetilde{r}^{2}>0$ have interstate commutes. The geography of the model is depicted in Figure 1 . In the figure, we depict the termini and the boundary for interstate commutes $\left(r_{T}^{1}, r_{T}^{2}, \widetilde{r}^{2}\right)$ along with the bid-rent curves. ${ }^{11}$ As individuals are mobile both within and between the two states, all individuals receive the same utility regardless of where they live or work. Equal utility within a state implicitly defines the bid-rent gradient as well as the population distribution in the state. ${ }^{12}$ It also follows that the residents living at the terminus in either state should obtain the same utility or

$$
V\left(w^{1}-c r_{T}^{1}-T^{1}, p^{*}\right)=V\left(w^{2}-c r_{T}^{2}-T^{2}, p^{*}\right)
$$

When states have reciprocity agreements meaning that taxes depend on the location of the household's residence, not their employment, an additional equilibrium condition is

$$
V\left(w^{2}-c \widetilde{r}^{2}-T^{2}, p^{2}\left(\widetilde{r}^{2}\right)\right)=V\left(w^{1}-c \widetilde{r}^{2}-S-T^{2}, p^{2}\left(\widetilde{r}^{2}\right)\right)
$$

In the absence of a reciprocity agreement between the states (no reciprocity), taxes are determined by location of employment and it must be the case that

$$
V\left(w^{2}-c \widetilde{r}^{2}-T^{2}, p^{2}\left(\widetilde{r}^{2}\right)\right)=V\left(w^{1}-c \widetilde{r}^{2}-S-T^{1}, p^{2}\left(\widetilde{r}^{2}\right)\right)
$$

Condition (2) and condition (3) state that individuals living in state 2 at the border between those who work in state 1 and those who work in state 2 are indifferent between the two options. The equilibrium also requires that the sum of the population in the two states equals the total population of the MSA. In a market equilibrium, the wage in each state must equal the marginal product of labor there given the level of employment:

$$
f_{1}^{\prime}\left(E_{1}\right)=w^{1} \text { and } f_{2}^{\prime}\left(E_{2}\right)=w^{2},
$$

\footnotetext{
${ }^{11}$ Of course, in equilibrium all individuals are indifferent between any location in the MSA as they have identical utility functions and costless mobility. Then while someone living in state 2 and working in state 1 need not live closer to the CBD than someone living in state 2 and working there, assigning them the location nearest the $\mathrm{CBD}$ in state 2 allows for clearer statements about the impacts of tax policies on interstate commutes.

${ }^{12}$ From the condition of equal utility within a state, $V\left(w^{i}-c r_{T}^{i}-T^{i}, p^{*}\right)=V\left(w^{i}-c r_{T}^{i}-T^{i}, p^{i}(r)\right), r<$ $r_{T}^{i}$, we obtain $\frac{d p^{i}(r)}{d r}=-\frac{c}{l\left(p^{i}(r)\right)}$ and $\frac{d p^{i}(r)}{d r_{T}^{i}}=\frac{c}{l\left(p^{i}(r)\right)}$.
} 
where employment in state 1 is $E_{1}=\int_{0}^{r_{T}^{1}} N^{1}(r) d r+\int_{0}^{\widetilde{r}^{2}} N^{2}(r) d r$ and $E_{2}=\int_{\widetilde{r}^{2}}^{r^{2}} N^{2}(r) d r$ in state 2 .

\subsection{Comparative Statics: An Increase in $T^{1}$}

Our interest is in how a change in the tax rate in one of the two states in the MSA affects the distribution of population and employment among the two states, wages, the size of the MSA in each state, and commuting times. The size of the state $\left(r_{T}^{i}, i=1,2\right)$ determines the rents throughout the state $\left(\frac{d p^{i}(r)}{d r_{T}^{i}}=\frac{c}{l\left(p^{i}(r)\right)}\right)$ and the state population as well. Intuitively, an increase in the terminus of the MSA in the state will increase the rent at any location within the state. How the change in the tax rate rate affects the size of the MSA within the state determines the impact of the tax change on rents and, therefore, the population in the state.

Differentiating (1) with respect to $T^{1}$ will yield the changes in both the termini and wage rates due to the tax change, while differentiation of (2) and (3) will yield the change in wages, enabling us to separately identify the effects on wages from those on the termini. Differentiating the labor market equilibrium conditions (4) establishes the relationship between changes in wages and employment in the two states that occur as a result of the increase in taxes in state 1.

\subsubsection{An Increase in $T^{1}$ with Reciprocity}

In the Appendix, we solve for $\frac{d w^{1}}{d T^{1}}, \frac{d w^{2}}{d T^{1}}, \frac{d r_{T}^{1}}{d T^{1}}, \frac{d r_{T}^{2}}{d T^{1}}$, and $\frac{d \widetilde{r}^{2}}{d T^{1}}$. In the case of reciprocity, the tax differential is not capitalized into wages:

$$
\frac{d w^{1}}{d T^{1}}=\frac{d w^{2}}{d T^{1}}=0
$$

but is fully capitalized into land prices,

$$
\frac{d r_{T}^{1}}{d T^{1}}=-\frac{1}{c} \frac{\frac{d N^{2}}{d r_{T}^{2}}}{D}<0, \text { and } \frac{d r_{T}^{2}}{d T^{1}}=\frac{1}{c} \frac{d N^{1}}{d r_{T}^{1}}=0
$$

and interstate commuting increases as well,

$$
\frac{d \widetilde{r}^{2}}{d T^{1}}=\frac{1}{c}\left[\frac{\frac{d N^{1}}{d r_{T}^{1}}}{\frac{d N_{\widetilde{r}^{2}}}{d \widetilde{r}^{2}}}\right]\left[\frac{\frac{d N^{2}}{d r_{T}^{2}}}{D}\right]>0
$$

where $D=\left[\frac{d N^{1}}{d r_{T}^{1}}+\frac{d N^{2}}{d r_{T}^{2}}\right]>0$ and $N_{\widetilde{r}^{2}}$ is the total number of interstate commuters. As seen in (5), the tax increase in state 1 has no impact on relative wages in the two states in the 
presence of reciprocity - instead the tax difference is capitalized into land prices. Then if $\frac{d w^{1}}{d T^{1}}=\frac{d w^{2}}{d T^{1}}$ and equilibrium in the labor market is to be maintained, the only possible equilibrium is to have no change in wage rates and therefore no change in the number employed in each state. However, the tax increase will reduce both the population density and the terminus of state 1 . It increases both density and the terminus in state 2 as a result of tax-induced migration. If employment in state 1 is unchanged but its population has decreased then the number of commuters from state 2 to state 1 must have increased.

The change in the bid rent functions as well as the termini of the MSA and boundary for interstate commutes $\left(r_{T}^{1}, r_{T}^{2}, \widetilde{r}^{2}\right)$ are illustrated in Figure 2. Denoting initial values with a superscript 0 , it shows a decrease in land prices in state 1 as well as a contraction of the terminus of the MSA there $\left(r_{T}^{1^{0}}>r_{T}^{1^{\prime}}\right)$. That decrease is offset by increase in land rents and the length of the MSA in state $2\left(r_{T}^{2^{\prime}}>r_{T}^{2^{0}}\right)$ resulting from the tax-driven migration. In addition, the distance that households are willing to commute from state 2 to state 1 increases $\left(\widetilde{r}^{\prime}>\widetilde{r}^{2^{0}}\right)$. This provides the intuition for our model: when states have reciprocity agreements, migration of households occurs from the high-tax state to the low-tax state. This intensifies the competition for land in the low-tax state, which increases rents throughout the state and expands the terminus of the city. Given employment in both the states must remain fixed, this implies more interstate commutes.

\subsubsection{An Increase in $T^{1}$ in the Absence of Reciprocity}

As with the case of reciprocity, we solve for $\frac{d w^{1}}{d T^{1}}, \frac{d w^{2}}{d T^{1}}, \frac{d r_{T}^{1}}{d T^{1}}, \frac{d r_{T}^{2}}{d T^{1}}$, and $\frac{d \widetilde{r}^{2}}{d T^{1}}$ in the Appendix. In the absence of a reciprocity agreement, tax differentials are not capitalized into land prices as shown by

$$
\frac{d r_{T}^{1}}{d T^{1}}=\frac{d_{T}^{2}}{d T^{1}}=0
$$

but are fully capitalized into wages,

$$
\frac{d w^{1}}{d T^{1}}=\frac{f_{1}^{\prime \prime}}{\left(f_{1}^{\prime \prime}+f_{2}^{\prime \prime}\right)}>0 \text { and } \frac{d w^{2}}{d T^{1}}=-\frac{f_{1}^{\prime \prime}}{\left(f_{1}^{\prime \prime}+f_{2}^{\prime \prime}\right)}<0
$$

with interstate commuting decreasing:

$$
\frac{d \widetilde{r}^{2}}{d T^{1}}=\frac{1}{N_{\widetilde{r}^{2}}\left(f_{1}^{\prime \prime}+f_{2}^{\prime \prime}\right)}<0
$$

If there is to be an equal movement $\left(\frac{d r_{T}^{1}}{d T^{1}}=\frac{d_{T}^{2}}{d T^{1}}\right)$ in the termini of the two states, to satisfy the population (land) market equilibrium the only possibility is to have $\frac{d r_{T}^{1}}{d T^{1}}=\frac{d_{T}^{2}}{d T^{1}}=0$. 
Figure 3 depicts the effects of the tax increase on land prices and the population distribution in the MSA in the absence of reciprocity agreements. As the figure shows, the limits of the MSA do not change nor do land prices change. The change in the distance that households are willing to commute from state 2 to state 1 decreases $\left(\widetilde{r}^{2^{0}}>\widetilde{r}^{2}\right)$. Intuitively, this result arises because in absence of reciprocity agreements, employment rather than people shift between the two states as a result of the tax increase. Taxes do not change residential location decisions because income is taxed on the basis of employment rather than residence. Here the income tax distorts the location of work, but not the location of residence.

We summarize the effects on the termini of the city and interstate commutes as a proposition.

Proposition 1. An increase in taxes in state 1 has the following equilibrium effects:

(a) When states have reciprocity agreements, the size (terminus) of state 1 will contract and the size of state 2 will increase. The number of commuters from state 2 to state 1 increases.

(b) When states do not have reciprocity agreements, the size (terminus) of state 1 and state 2 are unaffected by the tax increase, but the number of interstate commuters from state 2 to state 1 decreases.

Proof. See Appendix.

Although the focus of this paper is on the spatial distortion created by differences in taxes between states, these tax differentials have other interesting effects on capitalization and other urban quantities. The following corollary summarize these effects and represent fruitful areas of future empirical research.

Corollary 1. If states 1 and 2 have reciprocity [do not have reciprocity] agreements, an increase in taxes in state 1 has the following equilibrium effects:

(a) The population of state 1 will decrease [is unaffected] and the population of state 2 will increase [is unaffected];

(b) Land prices for any given distance ( $r$ ) from the CBD decrease [are unaffected] in state 1 and increase [are unaffected] in state 2;

(c) The population density (at any given $r$ ) in state 1 decreases [is unaffected] and increases [is unaffected] in state 2.

(d) Net wages in state 1 are unaffected [increase] and are unaffected [decrease] in state 2.

(e) Employment is unaffected [decreases] in state 1 and unaffected [increases] in state 2. Proof. See Appendix. 


\subsection{The Impact of an Increase in $T^{1}$ on Commuting Times}

The average commuting time in each state is given by

$$
\begin{gathered}
A C^{1}=\frac{1}{N^{1}} \int_{0}^{r_{T}^{1}} c r N^{1}(r) d r \\
\text { and } \\
A C^{2}=\frac{1}{N^{2}} \int_{\widetilde{r}^{2}}^{r_{T}^{2}} c r N^{2}(r) d r+\int_{0}^{\widetilde{r}^{2}}(c r+S) N^{2}(r) d r
\end{gathered}
$$

For state 1, the effect of the tax change on commute times is derived in the Appendix and given by:

$$
\frac{d A C^{1}}{d T^{1}}=\left[\frac{N_{T}^{1}}{N^{1}}\left(c r_{T}^{1}-A C^{1}\right)\right] \frac{d r_{T}^{1}}{d T^{1}}+\left[\frac{1}{N^{1}} \int_{0}^{r_{T}^{1}} N^{1}(r)\left(c r-A C^{1}\right) \hat{N}^{1}(r) d r\right] \frac{d r_{T}^{1}}{d T^{1}} .
$$

The effect of a tax increase on commuting times can be decomposed into two components. The first is the impact due to a change in the termini of the state. An expansion of the state's borders will increase average commute times as these commuters will have longer commutes than the average $\left(c r_{T}^{i}-A C^{i}>0\right)$. The sign of this term is simply the sign of $\frac{d r_{T}^{i}}{d T^{1}}$. The second term is more complicated. Intuitively, the sign of this term depends on how equilibrium changes in land prices in the state affect the distribution of the population. Specifically, in percentage terms, $\left(\hat{N}^{1}(r)\right)$, are the increases in population greater nearer the CBD where commuting costs are less than the average cost or near the fringe of the MSA where commuting costs are much higher?

As shown in the appendix, if the absolute value of the elasticity of demand of land, $\varepsilon=-\frac{d l}{d p} \frac{p}{l}>0$, is equal to unity then $\hat{N}^{1}(r)$, is a constant, that is, there are proportionate increases in population at all $r$. Then the second term will equal zero as $\int_{0}^{r_{T}^{1}} c r N^{1}(r) d r=$ $N^{1} A C^{1}$. If $\varepsilon \leq[>] 1$ then then the percentage changes in population density are greater [smaller] the further from the CBD and the term $\left(\frac{1}{N^{1}} \int_{0}^{r_{T}^{1}} N^{1}(r)\left(c r-A C^{1}\right) \hat{N}^{1}(r) d r\right)$ will be positive [negative].

For state 2, the first two terms of $\frac{d A C^{2}}{d T^{1}}$ are analogous to the two terms in (12) but there is an additional term associated with the additional cost of interstate commutes. We can express $\frac{d A C^{2}}{d T^{1}}$ as:

$$
\frac{d A C^{2}}{d T^{1}}=\left[\frac{N_{T}^{2}}{N^{2}}\left(c r_{T}^{2}-A C^{2}\right)\right] \frac{d r_{T}^{2}}{d T^{1}}+\left[\frac{1}{N^{2}} \int_{0}^{r_{T}^{2}} N^{2}(r)\left(c r-A C^{2}\right) \hat{N}^{2}(r) d r\right] \frac{d r_{T}^{2}}{d T^{1}}+\frac{N_{\widetilde{r}^{2}}}{N^{2}} S \frac{d \widetilde{r}^{2}}{d T^{1}}
$$

where the sign of the third term equals the sign of $\frac{d \widetilde{r}^{2}}{d T^{1}}$. 
In the absence of a reciprocity agreement, commuting times in state 2 decrease but are unaffected in state 1. This follows immediately from the fact that $\frac{d r_{T}^{1}}{d T^{1}}=\frac{d_{T}^{2}}{d T^{1}}=0$ and $\frac{d r^{2}}{d T^{1}}<0$ - the number of interstate commuters from state 2 to state 1 decreases. Of course, if the interstate commuters resided in state 1 and worked in state 2 , there would be an increase in average commuting as a result of an increase in the number of interstate commuters.

Proposition 2. An increase in the tax rate in state 1 will:

(a) decrease commute times in state 1 and increase commute times in state 2 when states have reciprocity agreements if the elasticity demand for land is equal to or less than 1;

(b) have no effect on average commute times in state 1, but will decrease commuting times in state 2 when no reciprocity agreements are in place.

Proof. See Appendix.

For the case of reciprocity states, this proposition follows immediately from the fact that with $\varepsilon \leq 1$, then the sign of $\frac{d A C^{i}}{d T^{1}}$ is simply the sign of $\frac{d r_{T}^{i}}{d T^{1}}$, which was negative. ${ }^{13}$ In state 2 , the terminus expands; in state 1 , the terminus contracts. For the case of no reciprocity states, the proposition follows from the changes to interstate commutes given there is no change in the terminus.

Given the importance of the price elasticity of land $(\varepsilon)$, a discussion of the empirical evidence on its value is in order. While this evidence is limited, Rothenberg et al. (1991) and Sirmans and Redman (1979) suggest that it is less than one and Gyourko and Voith (1999) find it to be approximately unity. We are unable to find any recent studies that suggest that it is greater than one, giving us confidence that our proposition can be signed as above. Intuitively the role of this elasticity is not surprising. If the change in land prices as a result of the change in the state terminus does not significantly affect the distribution of population within the state, perhaps resulting in an approximately proportional increase or decrease in population density at all $r$, the factor that determines whether commuting times increase or decrease will be whether the state's share of the MSA expands or contracts, thus increasing or decreasing the share of its commuters with longer than average commutes.

\subsection{Heterogeneous Individuals and Differential Taxation}

We next consider a simple model with two groups of individuals that have different skills and where production in each state depends on the employment of each group in that state. Income heterogeneity is important within an MSA and income groups often live in similar areas of the city; furthermore, individuals within an income group have similar tax rates.

\footnotetext{
${ }^{13}$ Note that for $\varepsilon>1$, it is still possible that Proposition 2a holds. It only reverses sign if $\varepsilon$ is sufficiently greater than 1 .
} 
Thinking forward to the empirical estimation, we wish to derive testable prediction whereby individuals are heterogeneous and have various tax rate differentials. Exploiting such heterogeneity will provide for more powerful evidence on the effect of taxes on commute times.

As might be expected, the analysis becomes more complicated with two groups. Two issues arise. First, consistent with empirical evidence, we assume that the low-skilled (lowincome) live nearer to the CBD. A second issue is whether the boundaries in the MSA between where the low-skilled and the high-skilled workers live $\left(\widehat{r}^{1}, \widehat{r}^{2}\right)$ are endogenous or not. We focus on the case in which there is a fixed boundary in each state between low-skilled and high-skilled workers (Voith and Gyourko 2002). This fixed boundary might be explained by fiscal zoning, existing housing stocks and public services, or a failure to assemble parcels (Brooks and Lutz 2013). In this setting, the area in the MSA devoted to low-income housing does not change, but the population density may. This means expansion or contraction of the MSA area is devoted to housing for high-skilled households.

Let there be $N_{H}$ individuals in the "high" skill group and $N_{L}$ in the "low" skill group in the MSA. As is the case with no heterogeneity, all workers commute to work in the CBD that is located in both states. Production in state $i$ is now given by $f^{i}\left(E_{H}^{i}, E_{L}^{i}\right)$ where

employment is given by $E_{H}^{1}=\int_{\hat{r}^{1}}^{r_{T}^{1}} N^{1}(r) d r+\int_{\hat{r}^{2}}^{{\widetilde{r_{H}}}^{2}} N^{2}(r) d r, E_{H}^{2}=\int_{\widetilde{r}_{H}^{2}}^{r^{2}} N^{2}(r) d r, E_{L}^{1}=$ $\int_{0}^{\hat{r}^{1}} N^{1}(r) d r+\int_{0}^{\widetilde{r}^{2}} N^{2}(r) d r$ and $E_{L}^{2}=\int_{r_{L}^{2}}^{\hat{r}^{2}} N^{2}(r) d r+$ and with $f_{j}^{i} \equiv \frac{\partial f^{i}}{\partial E_{j}^{i}}>0$ and $f_{j j}^{i} \equiv$ $\frac{\partial^{2} f^{i}}{\partial E_{j}^{i}}<0, i=1,2, j=H, L$. We simplify the analysis by assuming that $f_{L H}^{i}=0-$ the marginal productivity of high and low-skilled workers depends only on the number in that skill group in the state and not the number of workers in the other group. We assume that the utility function is of the form $U(x, l)=x+m_{j}(l), j=L, H$. The demand for land for each type can be expressed as $l_{j}(p), j=H, L$ where we assume that $l_{H}(p)>l_{L}(p)$, that is, high-skilled individuals demand more land than low-skilled individuals at any given rent, $p$. Then $w_{j}^{i}$ is the wage and $T_{j}^{i}$ is the tax for skill (income) type $j$ in state $i$. In equilibrium we assume that $w_{H}^{i}>w_{L}^{i}, i=1,2$, the high-skilled workers receive higher wages than low-skilled workers.

\subsubsection{Equilibrium Conditions}

Empirical evidence suggests that higher incomes concentrate further from the CBD in U.S. metropolitan areas. Then consistent with this observation and our assumption that $l_{H}(p)>$ $l_{L}(p)$ it follows that

$$
\left|\frac{d p_{H}(r)}{d r}\right|<\left|\frac{d p_{L}(r)}{d r}\right|
$$


Equation (14) is a single-crossing condition that states that the amount that high-income (skilled) individuals are willing to pay for land falls at a slower rate than that of the lowincome (skilled) individuals. ${ }^{14}$ In equilibrium, the low-income individuals will reside nearer the CBD and the high-income individuals live further away. High income individuals live between the terminus of the MSA in the State $1\left(r_{T}^{1}\right)$ and the terminus for the low-income individuals $\left(\hat{r}^{1}\right)$ while low-income individuals live between the interior terminus $\left(\hat{r}^{1}\right)$ and 0 . We assume that in equilibrium, for both the high-skilled and low-skilled, some workers reside in state 2 and work in state $1 .^{15}$

The termini condition for high-skilled workers is the same as in the case of a homogeneous population, (1), with $T_{H}^{j}$ replacing $T_{j}, j=1,2$. In addition a terminus condition for the low-income individuals arises,

$$
V\left(w_{L}^{1}-T_{L}^{1}-c \hat{r}^{1}, p^{1}\left(\hat{r}^{1}\right)\right)=V\left(w_{L}^{2}-T_{L}^{2}-c, \hat{r}^{2}, p^{2}\left(\hat{r}^{2}\right)\right)
$$

As in the case with a homogeneous population, the high-skilled interstate commuters must receive the same utility as the high-skilled workers who work and reside in state 2. Again the conditions for this are given by (2) for reciprocity and (3) for the case of no reciprocity with the substitutions $T_{H}^{j}$ for $T_{j}, j=1,2$.

Labor market clearing requires that marginal product equals the wage rate for both types of workers, (4). Finally, the sum of the populations of low-income and high income individuals in each state must equal the total population in the MSA.

\section{The Case with Reciprocity}

The impacts of an increase in a tax on high-skilled workers in state $1\left(T_{H}^{1}\right)$ is identical to that of the case with a homogeneous population - the tax rate is fully capitalized into land prices and has no effect on wages of the high-skilled workers. As a consequence, there will be an increase in the terminus in state 2 , a contraction in state 1 , and increased commuting from state 2 to state 1 . As a result, commuting times for high-skilled workers in state 1 decrease while they increase in state 2. As the boundaries are fixed for low-skilled workers, there is no affect on their population, wages nor employment and commutes. Low-skilled workers are unaffected by the increase in $T_{H}^{1}$.

In contrast, an increase in the tax on low-skilled workers in state $1\left(T_{L}^{1}\right)$ will have no effect

\footnotetext{
${ }^{14}$ The assumption that the bid-rent function decreases at a slower rate for high-income individuals is not critical to our analysis. If the opposite were true, then low-income individuals would live on the outskirts of the MSA and our predicted impacts would be reversed.

${ }^{15}$ Again, as with the case with a single group of workers, the division of interstate commuters and noninterstate commuters into two distinct sections of the state is completely arbitrary.
} 
on the termini of the MSA in either state nor on the wages of the high-skilled workers. This being the case, neither the population, employment, interstate commuting, nor commuting times for high-skilled workers change. The low-skilled results are similar to those for the high-skilled workers when a tax is placed on them - the tax rate is fully capitalized into land prices and has no affect on wages or employment. Interstate commuting from state 2 to state 1 increases and, therefore, the average commute time for low-skilled workers increases. As with the case with homogeneous workers, the impact on the average commute time in state 1 depends on whether the price elasticity of demand for land is greater or less than 1. If the $\varepsilon \leq 1$, the population reductions are smaller nearer the CBD, so a higher percentage of commuters now have longer trips and commute time; if $\varepsilon>1$ the population reductions are greater nearer the CBD meaning a higher percentage of commuters now have shorter commutes. There will be a reduction in interstate commuting from state 2 to state 1 meaning that commuting times of residents of state 2 should be reduced, while commutes for residents of state 1 are unaffected.

\section{The Case with No Reciprocity}

Again, the effects of an increase in the tax on high-skilled workers in state $1\left(T_{H}^{1}\right)$ on highskilled workers are identical to those with a homogeneous population - the termini of the MSA does not change in either state and the tax is fully capitalized into wages. The population of high-skilled workers in either state does not change, but employment in state 1 decreases and increases in state 2 . Then interstate commuting from state 2 to state 1 will fall. As a result average commute times for high-skilled workers in state 2 decrease, but the commute time in state 1 is unaffected. Low-skilled workers are unaffected by the change in $T_{H}^{1}$.

In the case of an increase in the tax on low-skilled workers $\left(T_{L}^{1}\right)$, as is the case with reciprocity, the tax increase has no effect on high-skilled workers. The impacts of the increase in $T_{L}^{1}$ on low-skilled workers are different from those when there is reciprocity but mirror those for an increase in $T_{H}^{1}$ for the high-skilled workers in the absence of reciprocity. The tax increase is fully capitalized into the wages of the low-skilled workers with no change in the populations of low-skilled workers in either state. Interstate commuting from state 2 to state 1 falls, meaning that commuting times of low-skilled residents of state 2 should be reduced while those of residents of state 1 are unaffected.

We summarize the results in this section in the following proposition:

\section{Proposition 3.}

(a) When state 1 and state 2 have a reciprocity agreement: 
(i) An increase in the tax on high-skilled workers in state $1\left(T_{H}^{1}\right)$ will contract the terminus and reduce commuting times of the high-skilled there with the opposite effects in state 2. Interstate commuting of high-skilled workers from state 2 to state 1 will increase. The increase in $T_{H}^{1}$ has no effect on the commuting times of low-skilled workers.

(ii) An increase in the tax on low-skilled workers in state $1\left(T_{L}^{1}\right)$ will increase both commute times for low-skilled workers in state 2 and interstate commutes from state 2 to state 1 for them. If the elasticity of demand for land $(\varepsilon)$ is less than or equal to unity then commuting times in state 1 will decrease. Neither termini nor the commute times of high-skilled labor are affected by the increase in $T_{L}^{1}$.

(b) When state 1 and state 2 do not have a reciprocity agreement:

(i) An increase in $T_{H}^{1}$ will have no effect on the termini of either state. There will be a reduction in interstate commuting of the high-skilled from state 2 to state 1 and, as result, a reduction in commuting times of the high-skilled in state 2. Commuting times of the the high-skilled in state 1 and the low-skilled in both states are unaffected by the tax increase.

(ii) An increase in $T_{L}^{1}$ will decrease commute times for the low-skilled in state 2 as interstate commuting from state 2 to state 1 for low-skilled workers decreases. Commute times for the low-skilled in state 1 and high-skilled in both states are unaffected by the tax increase.

Proof. See Appendix.

As suggested by the results summarized in the proposition, it is the difference in tax for individual households not aggregate nor average differentials for all households in the MSA that affect commute times for a particular individual households. This being the case, our empirical strategy focuses on identifying the difference in tax payments between the two states for individual households.

\subsection{Tax and Public Service Changes}

In general, taxes are used to fund spending. If changes in spending are valued equally with the associated changes in taxes $\left(M R S \frac{\Delta G}{\Delta T}=\triangle T\right)$ where $M R S$ is the marginal rate of substitution between the public and private goods, then tax differentials are not capitalized into either wages nor rents and no change in the location of residences or employment occurs. If the public good is overprovided, that is, the associated changes in spending are valued less than the associated changes in taxes $\left(M R S \frac{\Delta G}{\Delta T}<\Delta T\right)$ our results in the absence of a public service hold. If the public good is underprovided, $\left(M R S \frac{\Delta G}{\Delta T}>\triangle T\right)$, the impacts of tax increases are reversed. As it is most likely that high-income individuals are net payers into the tax system, we would expect the most salient effects to arise for high-income 
individuals and be consistent with our predictions made in the absence of tax-financed public services. It is interesting to note the analogy between property value and public service provision examined in Brueckner (1979) and Brueckner (1982) and commuting times and public service provision here. Our analysis here suggests a future "test" of the Tiebout hypothesis might be obtained by examining the impacts of balanced-budget tax increases on commuting times. If public services are efficiently provided, commuting times should be unaffected by marginal increases in taxes.

\subsection{Implications for Empirics}

The theoretical model has several implications for the empirical analysis. (1) Differences in average tax rates are important in multi-state MSAs. Higher marginal tax rates paid by the household will still result in more sprawling cities through the Wildasin (1985) channel, but we expect average tax rate effects to be large given they affect location within the MSA. (2) The effect of tax rates are different in MSAs with reciprocity agreements than those MSAs without them. This provides us with a powerful way of identifying the effects of taxes on commuting and suggests a split-sample analysis on the basis of reciprocity status. (3) The heterogeneous agents model suggests household-specific tax rates will affect commutes with the tax rate for the average household in the MSA being less important. (4) We expect to find the largest effects for high income households (and similarly for homeowners) given that these households are most likely not receiving spending benefits that are equal to the taxes paid into the system. (5) Commute times are a sufficient statistic for measuring the distortion from tax differentials as it captures both the effects on the termini and through interstate commutes.

\section{Data}

We use micro-level data to study the behavior of households in multi-state MSAs. We use household records from the IPUMS-USA public use data set (Ruggles et al. 2010). The IPUMS-USA provides a 1 in 100 national random sample of the one year American Community Survey (ACS). We use data from the 2005 though 2011 ACS, creating a repeated cross-section of seven years in length. Our data is only for households residing in a Combined Statistical Area (CBSA) that cross state lines. We also restrict the sample to households in the non-farm labor force.

The United States government defines CBSAs on the basis of commuting patterns such that most individuals in the CBSA share a common market. Figure 4 shows CBSAs that cross state borders. Sixty-one CBSA's cross state borders although some of the smaller contiguous CBSAs are merged together in our analysis because some of the Public Use Microdata Areas (PUMAs) that provide geographical identification in the ACS do not allows us to identify the 
specific CBSA in which they are located. The appendix, table (A.1) provides the descriptive statistics for the CBSAs used in the analysis. For the MSAs that cross into three or more states, we use all portions of the MSA; the results are robust to using the two most populated sides of the MSAs. For most of these three state MSAs, the population and employment in the smallest portion of the MSA is trivial; the exception to this rule is the Washington DC MSA.

For all of the CBSAs in our sample, we use the data in Rork and Wagner (2012) to determine if the states have reciprocity agreements. Given that reciprocity agreements do not change frequently, we have no changes that occur over the time period of our sample.

To calculate tax rates across the MSAs we calculate the federal plus state average tax rate and the marginal tax rate conditional on being in either state of the multi-state MSA using the NBER's TAXSIM program (Feenberg and Coutts 1993). When doing this exercise, we calculate the tax rate conditional on all income having been earned in the state of residence. We then calculate the tax rate conditional on all the income being earned in the other state of the CBSA. Such an assumption is reasonable given the common labor market of the MSA. We calculate the sum of the federal and state rate to allow for the deductibility of tax payments at the other level government. A caveat on the tax calculation is noteworthy. For anonymity reasons, the IPUMS data top-codes extremely high incomes and bottom-codes extremely large losses. In cases where the data are top-coded, we use the top-coded income to calculate tax liability. Some information needed to run TAXSIM are not reported to the Census; the appendix describes the details of the tax calculations, sample restrictions and the procedure for matching Census data to MSAs.

\subsection{Descriptive Statistics}

Our theoretical model suggests that the differences in household-specific average tax rates influences commute times by shifting populations and employment within the MSA. Here we provide simple scatter plots showing the relationship between average tax rate differentials and marginal tax rates and commuting times. The figures should be interpreted with caution as they contain no controls and are more useful at finding simple visual correlations.

In Figures 5-7, we present statistics where the unit of observation is the CBSA-state. As the theory notes, simply looking at the levels of taxes would not inform the extent of distortion to the urban spatial structure; it is the differences in tax rates that drives distortions to the termini (and thus commuting) of a city. For each CBSA, we calculate the mean marginal tax rate and the mean average tax rate differential relative to the other state in the CBSA, and the average commute time. We use ArcGIS to calculate the area and the perimeter on each side of the MSA. When aggregating to the CBSA-state level, the tax differential for state $s$ in metro area $m$ is defined as the difference in the mean tax rate on 
both sides of the borders. ${ }^{16}$ For marginal rates, we always use the average of the marginal tax rate that is paid by the tax payer because in Wildasin (1985), it is the marginal tax rate that is paid that changes the opportunity cost of time for households. For commute times, if two individuals live in a household, we add the commute times to derive the aggregate statistics across two- and one- person households.

On top of each scatter plot we fit a univariate regression line; the univariate regression is unweighted. It is immediately evident that average tax rate differentials have different effects on the land mass and perimeter of cities in states with reciprocity agreements relative to states without reciprocity agreements. Of course, CBSA areas and perimeters are defined by entire counties and are subject to some errors (Holmes and Lee 2010), so area may not be representative of commuting times. However, the pattern is quite similar for commute times. In general, the aggregate statistics show that most of the effect of the tax differences is in states that have reciprocity agreements; no relationship exists in the aggregated data for states in CBSAs without reciprocity. This result is consistent with the theoretical model where changes to commute times occurs through multiple reinforcing channels in reciprocity states. We also confirm Wildasin (1985)'s result in these scatter plots - that marginal tax rates are positively correlated with city size and commutes.

\section{Research Design}

We exploit policy discontinuities that arise at state borders within a CBSA to identify the effect of tax differences on commuting patterns and times. Discontinuous changes in taxes at borders have been used to study a variety of phenomenon including tax evasion and avoidance (Lovenheim 2008; Merriman 2010; Engel et al. 2013), tax incidence (Harding, Leibtag and Lovenheim 2012), migration decisions (Coomes and Hoyt 2008), firm location decision (Holmes 1998; Rohlin, Rosenthal and Ross 2012) and tax competition (Agrawal forthcoming; Eugster and Parchet 2013). Although the first three studies analyze tax evasion of cigarettes and license fees, the analogy is similar to the avoidance of income taxes. In our case, conditional on having a job in a particular CBSA, households may select either a state of residence or a state of work in order to avoid the higher tax liability.

We naturally focus on how state income taxes would differ between the states within the MSA given the household's reported income and its current employment. To study the effect of tax differentials on commuting, we also exploit household level variation within a CBSA, occupation and year. The identifying variation comes from person-specific differences in the average tax differential and marginal tax rates. To test how commute times vary as a function of the tax rate for household $i$ living in metropolitan area $m$ and state $s$, the most

\footnotetext{
${ }^{16}$ For three state MSAs the differential is the average tax rate in state $s$ minus the average of the tax rates in the other two states.
} 
complex specification we estimate is:

$$
C_{i, m, s}=\begin{gathered}
\alpha+\beta_{1} \triangle a t r_{i, m, s}+\beta_{2} \triangle a t r_{i, m, s} R_{m}+\gamma_{1} m t r_{i, m, s}+\gamma_{2} m t r_{i, m, s} R_{m} \\
+\vartheta R_{m}+\varrho X+\zeta+\delta+\omega+\epsilon_{i, m, s}
\end{gathered}
$$

where $C$ is the total commute time of the household, $\triangle a t r$ is the difference in average tax rates, $m t r$ is the marginal tax rate paid, $X$ are controls listed in the appendix, $R$ is a dummy variable that equals one if the states have a reciprocity agreement, $\zeta$ are CBSA fixed effects, $\omega$ are occupation fixed effects and $\delta$ are year fixed effects. We also estimate the model splitting the sample by reciprocity status. Let

$$
\triangle a t r_{i, m, s}= \begin{cases}a t r_{i, m, s}-a t r_{i, m,-s} & \text { if two state CBSA } \\ a t r_{i, m, s}-\overline{a t r_{i, m,-s}} & \text { if more than two state CBSA }\end{cases}
$$

where $a t r_{i, m, s}$ is the average tax rate (federal plus state) of household $i$ living in state $s$ of MSA $m$ and $a t r_{i, m,-s}$ is the average tax rate for that same household in the other state (denoted $-s$ ) of the urban area. Define $\overline{a t r_{i, m,-s}}$ as the average (for that household) across the other two states in the CBSA for three-state areas. The idea behind using the average of all other states in the CBSA is that even though the third state is less populated, it is within the common labor market as defined by the government and thus households can choose it as a location. The practice of using the mean of the tax rate in three state MSAs follows Coomes and Hoyt (2008). Thus, $\triangle a t r_{i, m, s}$ is the average tax rate in the household's state of residence relative to the rate in the counter-factual (non-residence) portion of the MSA. ${ }^{17} \mathrm{We}$ follow the convention in the theoretical model and determine the tax impacts on commute times on the basis of the state of residence. Notice a household's counter-factual is what they would pay to the other state given its income and other characteristics determining its tax liability; it is not based on what a representative (average) household would pay to the other state. As tax brackets and progressivity differ across states, it is important to look at the effect of the tax differential conditional on having a given level of taxable income; the common labor market of the MSA allows us to do so.

To account for the effect of marginal tax rates on the opportunity cost of time, we use the marginal tax rates paid as calculated by TAXSIM. Let the marginal tax rate paid of an

\footnotetext{
${ }^{17}$ The specification imposes that the response is linear in this variable. We show in Appendix Table A.2, that the results are robust to flexible functions.
} 
household living in state $l$ and working in state $w$ be

$$
m t r_{i, m, s}= \begin{cases}m t r_{i, m, l} & \text { if } R_{m}=1 \\ m t r_{i, m, w} & \text { if } R_{m}=0\end{cases}
$$

where $m t r$ is the marginal tax rate. Notice that the value depends on whether the states in the MSA have a reciprocity agreement. In words, $m t r_{i, m, s}$ equals the marginal tax rate in your state of residence if the states have reciprocity and equals the tax rate your state of work if no reciprocity agreement exists. Unlike the average tax rates, the marginal tax rate is based on the tax rate that you actually pay because as in Wildasin (1985), the marginal tax rate influences the cost of your time. No counter-factual is needed as the effect on the opportunity cost of time is not relative to what occurs in the other state.

The implicit identifying assumption for $\triangle a t r$ is that we can accurately measure the counter-factual tax rate when we only observe wages from one state. If wages differ dramatically across states, we will mismeasure the counter-factual. In MSAs with reciprocity, this amounts to assuming that if the household changed residences, their wages would remain similar. In MSAs without reciprocity, this implies that if the household changed the state of work, net-of-tax wages would remain the same. We rely on the MSA being a local labor market and thus, the wages available to a household of a particular ability level are independent of the particular state. We address possible violations of this assumption in the robustness checks.

To address the possibility of confounding factors, we employ a battery of controls within the $X$ matrix including social and demographic characteristics that are designed to control for household preferences for public goods and characteristics. These controls include marital status, race, income, gender, the number of children, citizenship, age, employment status, whether the individual works from home, education status, and whether the individual works outside of the MSA. We realize the relationship between commutes and incomes may be non-linear, so we include a flexible polynomial in income as a control. Critically, in addition to these variables, we also include a series of occupation dummy variables such that all identifying variation from tax differences comes within an occupation. These dummy variables critically control for the fact that certain occupations may cluster on one side of a state border. Because the analysis is done at the household level, we also include person-specific characteristic and occupation variables for the second person after interacting them with a variable that equals one if it is a two person household. ${ }^{18}$ In addition to these demographic

\footnotetext{
${ }^{18}$ Inclusion of both person's characteristics is common when households face joint decisions. For example, see McGeary (2009).
} 
controls we also include a dummy variable that equals one if the central city is located in the state of residence for the household and a dummy variable for whether the household works in the central city.

As discussed in section 1.3 taxes are used to fund spending. If changes in spending are valued equally with the taxes that finance them, tax differentials will not affect commuting times. Further, a state with relatively low income taxes may have relatively high burdens in terms of other taxes. If a difference in income taxes between two states is offset by another tax, then, again, no capitalization will occur and commute times would be unaffected. This being the case, we control for other policy variables within the MSA including per pupil educational spending on each side of the MSA, (log) school enrollment, the gas tax differential, the sales tax differential, the differential in highway spending, and property tax rates paid by the household if a homeowner. In addition to controlling for these policies in our regression specification, we would note that it is extremely unlikely for high-income individuals to value the public goods being provided at par to the taxes paid and therefore expect the largest effects for these individuals. In addition, state income tax revenue will be used to fund expenditures state-wide and that MSAs (which have higher incomes on average) will likely pay more into the tax system, while spending will be more focused in lower income portions of the state.

\subsection{Reciprocity Agreements}

Reciprocity status is a key source of identifying variation. What causes this variation and is it likely to be correlated with unobserved determinants of commute times? Reciprocity agreements remain understudied despite their importance in determining the effective income tax rate that households pay. To address possible concerns regarding reciprocity status, we first note that most reciprocity agreements were implemented in the 1960s and 1970s. The most recent reciprocity agreement was implemented in 1992. In fact, only two reciprocity agreements have been passed since 1990 and only two reciprocity agreements have ever been abolished after their initial agreement. Given that reciprocity agreements were historically drawn, we are confident that the agreements have little relationship to current day variables. Still, we want to verify this claim and do so by running a regression of the form:

$$
\hat{R}=\alpha+\beta Z+\epsilon
$$

where $\hat{R}$ is a reciprocity dummy variable and where $Z$ is an observable characteristic from 2011. We run two types of regressions: (1) a state level regression where $\hat{R}$ takes on the value of one if the state has at least one reciprocity agreement and (2) a border analysis where we

pair adjoining states in our sample and let $\hat{R}$ equal one if that pair of states has a reciprocity 
agreement. In the first regression, the set of $Z$ includes the mean 2011 marginal tax rate in the state, the average tax rate in the state, the average commute time, and the fraction of residents with an interstate commute. In the second regression, we use the absolute value of the differential in all of these variables. Table 1 shows the results.

In the state-level results, only the average tax rate offers any explanatory power of the reciprocity variable. This result is entirely driven by Washington D.C.'s high tax rate; if the District of Columbia is removed from the sample, the results disappear. In the borders-based regression, average tax rate differentials across states and commute time differences in 2011 provide little predictive power as to whether the states have a reciprocity agreements. In places where one state has a high number of interstate commuters relative to the other state, the states are more likely to have reciprocity agreements. We take these results as strong evidence that current policies and commute times have very little influence on reciprocity status across the states.

\section{Results}

As can be seen in Table 2, the mean combined federal and state atr across all years in the sample is $7.5 \%$ and the average commute time is just over twenty-eight minutes. ${ }^{19}$ Approximately $7 \%$ of households have an interstate commute.

In Table 3 we present the baseline results of estimating (16). The columns in the table build sequentially from a univariate regression by adding fixed effects, then demographic, household, and state policy controls. We conduct two types of an analysis: a split sample analysis on the basis of reciprocity agreements and a pooled analysis. Our preferred specifications are (7)-(9), which include CBSA fixed effects, year fixed effects, household controls and other state policy differentials as well as industry dummies with clustered standard errors at the CBSA level.

The results in column (9) can be interpreted as follows. With respect to the average tax rate differential, a one percentage point increase in the tax differential increases commutes by 0.07 minutes in MSAs without reciprocity, but decreases commutes by $0.18(=.073-$ .251) minutes in MSAs with reciprocity. Given the empirical evidence suggests $\varepsilon \leq 1$, this asymmetric effect is a powerful result that is consistent with our theory. The implication is that in MSAs with reciprocity, increases in the average tax rate in a state relative its neighbor

\footnotetext{
${ }^{19}$ We check our average tax rate calculations from TAXSIM with statistics released by SOI and the CBO. For example, in 2007, the average atr was $9.3 \%$. We calculate an average of $9.0 \%$ (inclusive of state taxes) and thus we slightly underestimate the atr in the full population. The main reason for this slight downward bias is a result of the top coding of income data available to us. Of course, we only have a sample of the multi-state MSAs and for this reason as well, we do not expect the numbers to align perfectly. However, comparing simple statistics we derive with the data released by the government, we are confident in our ability to measure the atr.
} 
will shorten commutes as the terminus shrinks and more employment shifts to that state. In an MSA with no reciprocity agreement, an increase in the tax rate shifts employment out of the state and holds fixed the terminus - thus increasing inter-state commutes. A one percentage point increase in the marginal tax rate increases commute times by 0.04 minutes (or two and a half seconds). Although this effect is small, it is strongly significant and consistently significant in all of the robustness checks. This result suggests that the Wildasin (1985) effect is statistically important, but that the economic effect of marginal tax rates on the distorted shape of the city are relatively small. These effects may be small because marginal tax rates may not be salient to the household.

Although the full sample results are economically small, the theoretical model predicts that we should find larger responses for high-income individuals and perhaps no responses for other sub-groups. Estimation in the full sample includes many households who we expect are not influenced by average tax differentials - including lower income households and renters. We expect to find more significant impacts when stratifying the sample by income and home-ownership status.

\subsection{Heterogeneity by Income and Homeownership}

Now we turn to convincing sources of heterogeneous responses. Based on our theory, we expect that higher income households are more responsive to average tax rate differentials. High income households may have an easier time of moving or changing jobs within or across MSAs. Furthermore, higher income households are more likely to use paid tax preparers who may advise them of their tax situation. Finally, for any given difference in average tax rate differential, the difference in total taxes is greater the higher the household income. We would also expect tax differentials to be most salient for high income earners and the amount of taxes paid well above any possible offset from additional public good provision. To test this theory we cut the sample based on various income thresholds and compare the coefficients across the columns in table 4. We focus on households who earn below 30,000 dollars (the bottom quartile), households above the median income $(\$ 52,000)$, households above the mean household income $(\$ 72,000)$, and "superstar" households (above $\$ 500,000)$.

It becomes noticeable that the effect of marginal tax rates on commute times is relatively small for all types of households. The effect of the average tax rate differential is increasing across the income distribution. In MSAs where there are no reciprocity agreements, the effect for superstar households is almost four times as large as the effect on households with income above the median. In MSAs with reciprocity, the effects on superstar households are almost 6.5 times as large as households with income above the median. For superstar households, even small differences in their atr may result in large income changes. Noticeably, even for superstar households, as predicted by theory the effect of the tax differential is positive in 
MSAs that have no reciprocity agreements, but negative in those MSAs with agreements.

For high-income households, the effect of average tax rate differentials are economically and statistically significant even though marginal tax rate effects are economically small. For example, consider households earning above $\$ 500,000$. For these households, in MSAs without reciprocity, the effect of a one percentage point increase in the differential changes commute times (in one direction) by almost a minute. In MSAs with reciprocity, the effect is almost two minutes.

Further convincing evidence is obtained by dividing the sample on the basis of homeownership status. Consistent with what we might expect, Table 4 also shows that the effects are larger for homeowners than for renters - in fact, we find no effects for renters. Renters are more likely to have lower incomes and are more likely to move frequently. When we study low-income (less than $\$ 30,000$ and $\$ 75,000$ ) homeowners, they also have large responses in reciprocity states relative to renters.

\subsection{The Role of Land Use Regulations}

The model suggests that one channel through which commute times are affected is sprawl. This requires that the MSA has room to expand, however, Saiz (2010) shows that many MSAs are constrained by geography. In addition to geographic constraints, the results require that the expansion not be hindered by land use regulation. Fortunately, a large portion of the sample appear to be on major rivers (the Ohio, Missouri, Mississippi, etc.) which generally have ample room for expansion and are not known for extensive land use regulation. As a first attempt at determining the role of regulations and geography, we divide the sample into MSAs that are entirely divided by a river and MSAs that have linear borders (or are only partially split by a river). We find stronger effects in MSAs delineated by major rivers.

This leads us to naturally focus on the role of land use regulations. Gyourko, Saiz and Summers (2008) measure the intensity of land use regulations across cities. In their data, the authors also construct MSA level measures of land use regulations. ${ }^{20}$ Splitting the sample into the most restrictive quartile of zoning regulations and the least restrictive set of zoning regulations, it is easy to see in table 5 that the results are statistically significant only when the zoning regulations are not restrictive. This is especially the case for high-income individuals living in places not restricted by zoning regulations. This split sample analysis adds to the heterogeneous effects on the basis of reciprocity status and income level; the results are again consistent with what we would expect. When land-use regulations are restrictive, expansion of the MSA is more difficult and the channels in our model get closed down. Commute times are most responsive in areas where land use expansion is not heavily

\footnotetext{
${ }^{20}$ Some of the smaller micropolitan CBSAs do not appear in the Wharton index and they are omitted from the subsequent analysis.
} 
regulated.

\subsection{Robustness}

One concern may be the endogeneity of the average tax rate differential. Although we observe wages in the Census, we do not observe the counter-factual wages that the person would obtain in the other state of the MSA. Until now, our identifying assumption has been that the counter-factual wages are similar - in fact the same - across all states with in the MSA. Given that MSAs are defined as common commuting and labor markets, this seems like a reasonable assumption. However, one may be concerned about this issue especially in large MSAs. As noted in Kleven, Landais and Saez (2013) - in the context of superstar migration across countries - the counter-factual average tax rate will be over-estimated (because the tax systems are generally progressive) if households are more likely to select the side of the MSA where they can obtain the highest wages - raising endogeneity concerns. Although we think this concern is less likely in the case of multi-state MSAs and for our sample, we note that as in Kleven, Landais and Saez (2013), the marginal tax rate is exogenous to earnings - especially for high-income households in the top state income tax bracket. Although our specification includes the marginal tax rate paid by the household, we can construct the difference in the marginal tax rate in the state of residence and the marginal tax rate in the counter-factual state(s). As a robustness check we use this marginal tax rate differential as an instrument for the average tax rate differential. The exclusion restriction requires that the household's difference in marginal tax rates within the MSA does not directly affect commute times after controlling for observables including the marginal tax raid paid by the household. We simply mean this exercise as a robustness check; our preferred method of dealing with this concern is to argue that within the common labor market of the MSA, we do not substantially mismeasure the counter-factual earnings.

The results of the IV strategy are presented in Table 6. The first stage F statistic is strong and, as is evident, the marginal differentials are positively correlated with the average differentials. Comparing the results to column (7) and (8) of Table 3, the effects of the average tax rate differentials more than double for the full sample. For high-income households the results are similar although the standard errors become larger. Key to this result is that all of the signs - which are most important to link our empirics back to the theoretical result survive the IV strategy.

A final robustness exercise in this table is done to account for the fact that large MSAs get a great deal of weight in the regression specifications. For example, from Table A.1 it is clear that approximately two-ninths of the sample are households in the New York CBSA.

As we do not want to derive results that are dominated by a single CBSA and want results that broadly generalizable, we re-estimate our baseline specification such that each MSA 
in the data set is given equal weight. This weighting approach treats Logan, UT and New York City as equally sized clusters in the data. The results are strikingly similar, suggesting that our previous finding are not driven by an idiosyncratic component specific to the large metropolitan areas.

In Table A.4 (Appendix), we also show that the results are robust to using a dummy variable approach for the high-tax state, to using the average tax differential in the MSA and to restricting the sample to two-state MSAs.

\subsection{Monetary Costs of Commutes}

It would be useful to have a rough idea of the economic impact from these tax rate differentials. Brownstone and Small (2005) estimate the median willingness to pay to reduce commute times at thirty dollars an hour although noting substantial heterogeneity. Using the largest coefficient estimates of the effects of the marginal tax rate (coefficient 0.13), a one percentage point increases in marginal tax rates increases commute times by 8 seconds per trip. Assuming an individual travels two trips (round trip) per day, works five days a week for fifty-two weeks, this would result in an added cost of travel of approximately $\$ 35$ dollars a year. This is an economically small magnitude.

Using the median willingness to pay and the average tax rate results for households earning more than $\$ 52,000$ in Table 4 , we can also translate minutes to dollars. A one percentage point change in the difference in average tax rates raises commutes by .24 minutes in MSAs without reciprocity and lowers them by .32 minutes in MSAs with reciprocity agreements. Here the effect rises to approximately $\$ 70$ a year. This represents a lower bound given that these higher-income households likely value their time more so. For households with incomes over $\$ 500,000$ the effect in MSAs with reciprocity is approximately $\$ 540$ per year if these households value their time at $\$ 30$ an hour. Instead, if we use these household's labor earnings to place a value reflecting an opportunity cost of time based on an estimated hourly wage, we obtain an effect over \$2000 a year in MSAs with reciprocity. Given a one percentage point change in the difference in average tax rates changes tax payments by just over $\$ 5000$, this is a significant fraction of the change in tax payments that is offset through commuting.

Average tax rate differentials have economically meaningful effects - especially for highincome households - but marginal tax rates have relatively small economic effects. This suggests average tax rates are highly salient.

\section{Conclusion}

We present robust evidence that differences average tax rates distort a city's spatial reach, change commute times and commuting patterns. The mechanism by which average tax rates 
have such an effect is through changes in location of residents and employment. When taxes are paid based on the location of residence, people will choose to reside in the lower tax side of the city thereby expanding that side of the city. When taxes are paid on the location of employment, firms move and tax avoidance occurs through changes in interstate commuting patterns. In our empirical application, we are able to identify effects of differences in average tax rate in multi-state MSAs that are opposite in sign between MSAs with reciprocity and those without it.

For purposes of this paper, we do not attempt to identify whether commutes are longer because of interstate commutes or because of expansion of the terminus. ${ }^{21}$ Our model shows that commute times are a sufficient measure of this distortion and thus we focus on this measure. We think that future research might address this question by analyzing precisely geo-coded data on location of residence and work. Both expansions of the termini and changes in interstate commuting patterns are costs associated with tax differences within the MSA. Future research might also explore the effect of differences in average tax rates on density, capitalization into wages and rents, and employment as summarized in corollary 1.

This paper suggests that policy discontinuities within an MSA have important implications for the efficient allocation of jobs and people within cities. Because policies, regulations, and spending vary not only across cities, but within cities, this paper expands our understanding of decentralized governance in urban areas.

\section{References}

Agrawal, David R. forthcoming. "The Tax Gradient: Spatial Aspects of Fiscal Competition." American Economic Journal: Economic Policy.

Alonso, William. 1964. Location and Land Use. Harvard University Press.

Anas, Alex, and Leon N. Moses. 1979. "Mode Choice, Transport Structure and Urban Land Use." Journal of Urban Economics, 6: 228-246.

Baum-Snow, Nathaniel. 2007. "Did Highways Cause Suburbanization?" Quarterly Journal of Economics, 122(2): 775-805.

\footnotetext{
${ }^{21}$ To attempt to address this issue, we tried to test the effect of tax differentials on a binary variable for whether the household had an interstate commute. Given that the sample is mostly composed of zeros, we were unable to find sufficient variation to identify any effects. In fact, observable non-tax variables had very little predictive power on this dimension. We also lack data on the precise commuting distance to then be able to disentangle the two effects.
} 
Baum-Snow, Nathaniel. 2010. "Changes in Transportation Infrastructure and Commuting Patterns in U.S. Metropolitan Areas, 1960-2000." American Economic Review Papers G3 Proceedings, 100(2): 378-382.

Bleakley, Hoyt, and Jeffrey Lin. 2012. "Portage and Path Dependence." Quarterly Journal of Economics, 127: 587-644.

Brooks, Leah, and Byron Lutz. 2013. "From Today's City to Tomorrow's City: An Empirical Investigation of Urban Land Assembly." George Washington University Working Paper.

Brownstone, David, and Kenneth A. Small. 2005. "Valuing time and reliability: assessing the evidence from road pricing demonstrations." Transportation Research Part A, 39: 279-293.

Brueckner, Jan K. 1979. "Property values, local public expenditure and economic efficiency." Journal of Public Economics, 11(2): 23-245.

Brueckner, Jan K. 1982. "A test for allocative efficiency in the local public sector." Journal of Public Economics, 19(3): 311-331.

Brueckner, Jan K., and Hyun-A Kim. 2003. "Urban Sprawl and the Property Tax." International Tax and Public Finance, 10: 5-23.

Calabrese, Stephen, Glenn Cassidy, and Dennis N. Epple. 2002. "Local Government Fiscal Structure and Metropolitan Consolidation." Brookings-Wharton Papers on Urban Affairs, 1-32.

Calabrese, Stephen M., Dennis N. Epple, and Richard E. Romano. 2012. "Inefficiencies from Metropolitan Political and Fiscal Decentralization: Failures of Tiebout Competition." Review of Economic Studies, 79(3): 1081-1111.

Coomes, Paul A., and William H. Hoyt. 2008. "Income Taxes and the Destination of Movers to Multistate MSAs." Journal of Urban Economics, 3: 920-937.

de Bartolome, Charles A.M., and Stephen L. Ross. 2003. "Equilibria with Local Governments and Commuting: Income Sorting Vs. Income Mixing." Journal of Urban Economics, 54(1): 1-20.

Engel, Melissa, Gerlinde Fellner, Rupert Sausgruber, and Christian Traxler. 2013. "Higher Taxes, More Evasion? Evidence from Border Notches in TV License Fees." Working Paper. 
Eugster, Beatrix, and Raphäel Parchet. 2013. "Culture and Taxes: Toward Identifying Tax Competition." University of St. Gallen Working Paper 2013-39.

Feenberg, Daniel, and Elisabeth Coutts. 1993. "An Introduction to the TAXSIM Model." Journal of Policy Analysis and Management, 12(1): 189-194.

Gerritse, Michiel. 2013. "Tax Competition with Commuting Workers and Agglomeration." VU University Amsterdam Working Paper.

Glaeser, Edward L., and Matthew E. Kahn. 2004. "Sprawl and Urban Growth." Handbook of Regional and Urban Economics, 9(56): 2481-2527.

Gyourko, Joseph, Albert Saiz, and Anita Summers. 2008. "A New Measure of the Local Regulatory Environment for Housing Markets: The Wharton Residential Land Use Regulatory Index." Urban Studies, 45(3): 693-729.

Gyourko, Joseph, and Richard Voith. 1999. "The Price Elasticity of the Demand for Residential Land." Lincoln Institute of Land Policy Working Paper WP99JG1.

Harding, Matthew, Ephraim Leibtag, and Michael Lovenheim. 2012. "The Heterogeneous Geographic and Socioeconomic Incidence of Cigarette Taxes: Evidence from Nielsen Homescan Data." American Economic Journal: Economic Policy, 4(4): 169-98.

Holmes, Thomas J. 1998. "The Effect of State Policy on the Location of Manufacturing: Evidence from State Borders." The Journal of Political Economy, 106(4): 667-705.

Holmes, Thomas J., and Sanghoon Lee. 2010. "Cities as Six-bySix-Mile Squares: Zipf's Law?" In Agglomeration Economics. , ed. Edward Glaeser, 105-131. National Bureau of Economic Research.

Kleven, Henrik Jacobsen, Camille Landais, and Emmanuel Saez. 2013. "Taxation and International migration of Superstars: Evidence from the European Football Market." American Economic Review, 103(5): 1892-1924.

Lovenheim, Michael F. 2008. "How Far to the Border?: The Extent and Impact of CrossBorder Casual Cigarette Smuggling." National Tax Journal, 61(1): 7-33.

McGeary, Kerry Anne. 2009. "How Do Health Shocks Influence Retirement Decisions?" Review of Economics and the Household, 7(3): 307-321.

McKenzie, Brian. 2013. "Out-of-State and Long Commutes: 2011." U.S. Department of Commerce Economics and Statistics Administration. 
Merriman, David. 2010. "The Micro-geography of Tax Avoidance: Evidence from Littered Cigarette Packs in Chicago." American Economic Journal: Economic Policy, 2(2): 61-84.

Mills, Edwin. 1972. Studies in the Structure of the Urban Economy. Johns Hopkins University Press.

Muth, Richard. 1969. Cities and Housing. University of Chicago Press.

OECD. 2014. "OECD Family Database." Social Policy Division - Directorate of Employment, Labour and Social Affairs. LMF2.6: www.oecd.org/social/family/database.

Rohlin, Shawn, Stuart S. Rosenthal, and Amanda Ross. 2012. "Tax Avoidance and Business Location in a State Border Model." Syracuse University Working Paper.

Rork, Jonathan C., and Gary A. Wagner. 2012. "Is There a Connection Between Reciprocity and Tax Competition?" Public Finance Review, 40(1): 86-115.

Rothenberg, Jerome, George C. Galster, Richard V. Butler, and John R. Pitkin. 1991. The Maze of Urban Housing Markets. University of Chicago Press.

Ruggles, Steven, J. Trent Alexander, Katie Genadek, Ronald Goeken, Matthew B. Schroeder, and Matthew Sobek. 2010. "Integrated Public Use Microdata Series: Version 5.0 [Machine-readable database]." Minneapolis: University of Minnesota.

Saiz, Albert. 2010. "The Geographic Determinants of Housing Supply." Quarterly Journal of Economics, 125(3): 1253-1296.

Schrank, David, Bill Eisele, and Tim Lomaz. 2012. "TTI's 2012 Urban Mobility Report Powered by INRIX Traffic Data." Texas A\&M Transportation Institute.

Sirmans, C. F., and Arnold L. Redman. 1979. "Capital-Land Substitution and the Price Elasticity of Demand for Urban Residential Land." Land Economics, 55(2): 167-176.

Tiebout, Charles. 1956. "A Pure Theory of Local Expenditures." Journal of Political Economy, 64(5): 416-424.

Voith, Richard, and Joseph Gyourko. 2002. "Capitalization of federal taxes, the relative price of housing, and urban form: density and sorting effects." Regional Science and Urban Economics, 32(6): 673-690.

Wildasin, David E. 1985. "Income Taxes and the Urban Spatial Structure." Journal of Urban Economics, 18: 313-333. 
Young, Christobal, and Charles Varner. 2011. "Millionare Migration and State Taxation of Top Incomes: Evidence from a Natural Expirement." National Tax Journal, 64(2): 255-284. 
Figure 1: Geographic Layout and Equilibrium

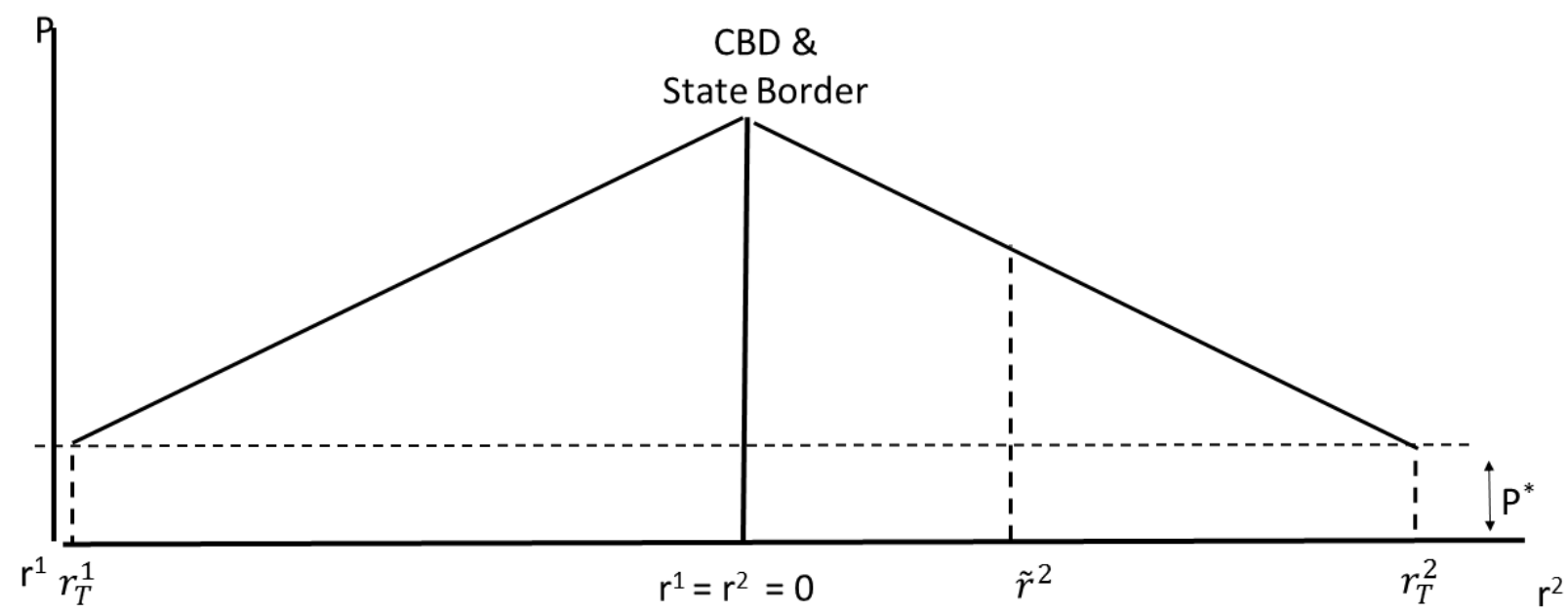

Figure 2: An Increase in the Tax with Reciprocity

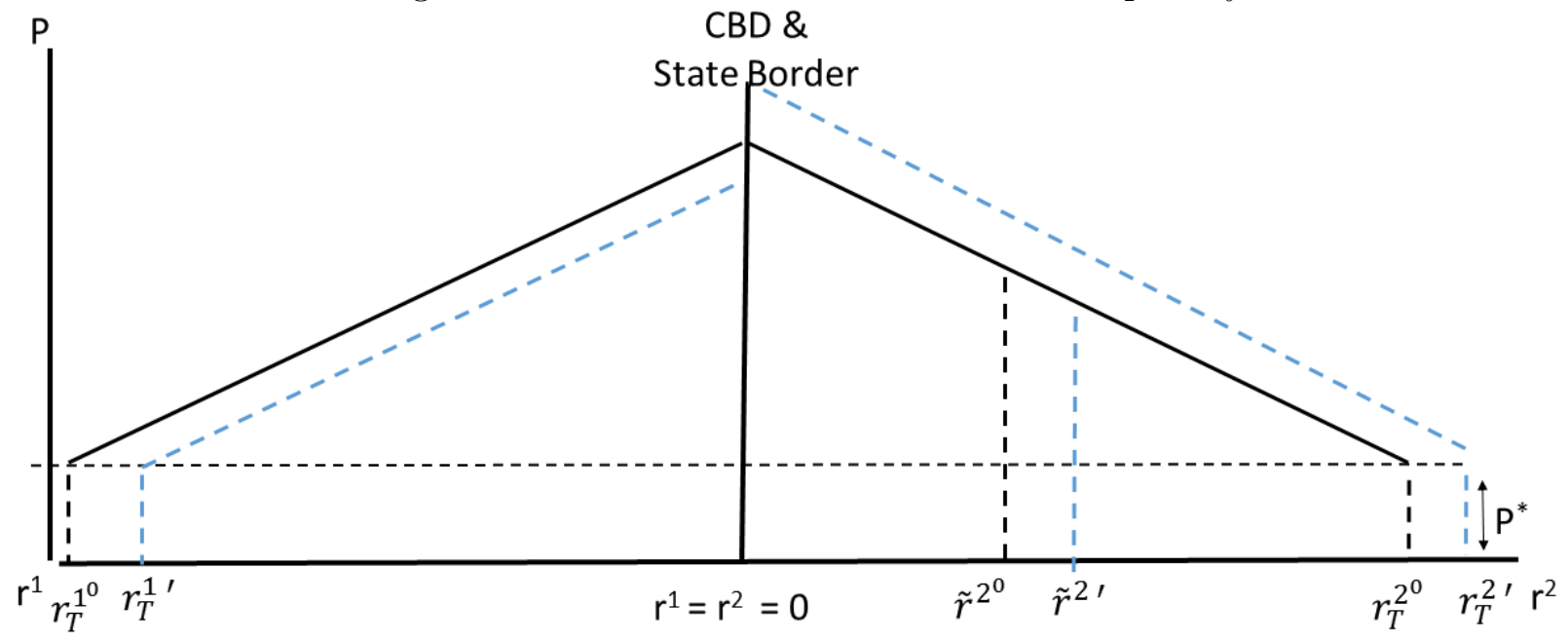

Figure 3: An Increase in the Tax with No Reciprocity

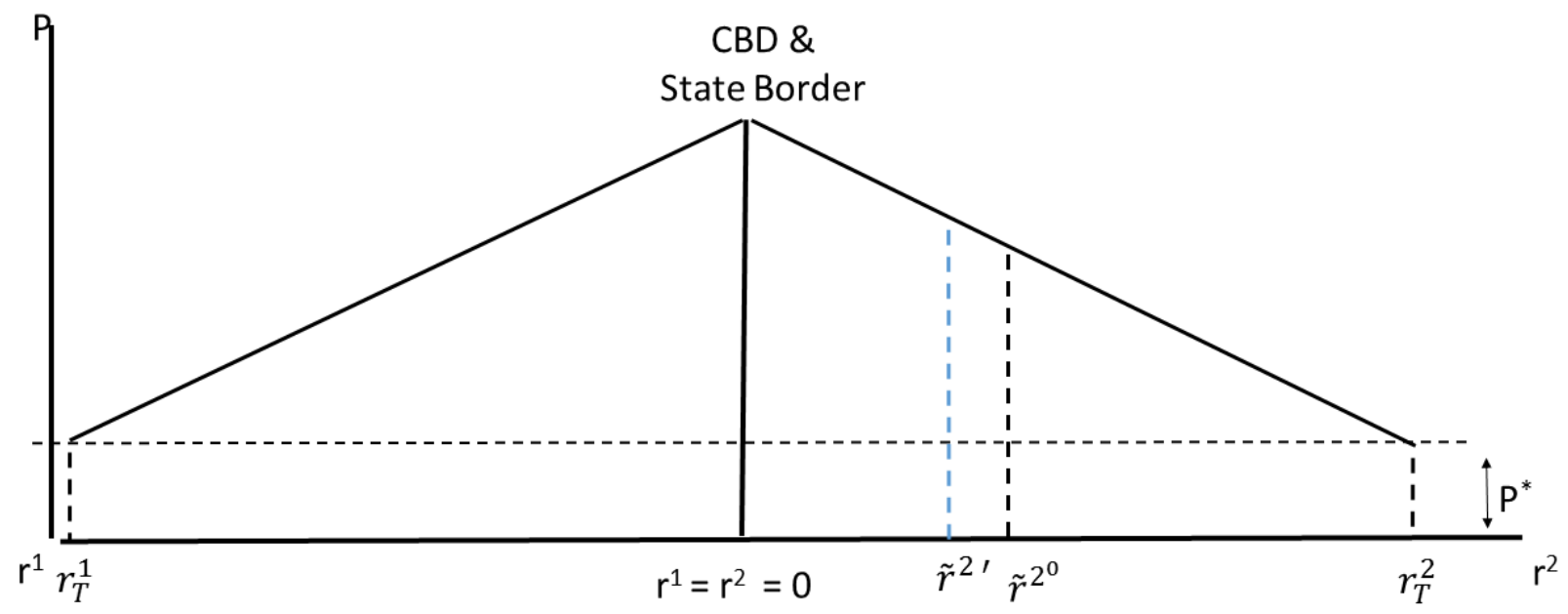


Figure 4: Map of Multi-State CBSA's

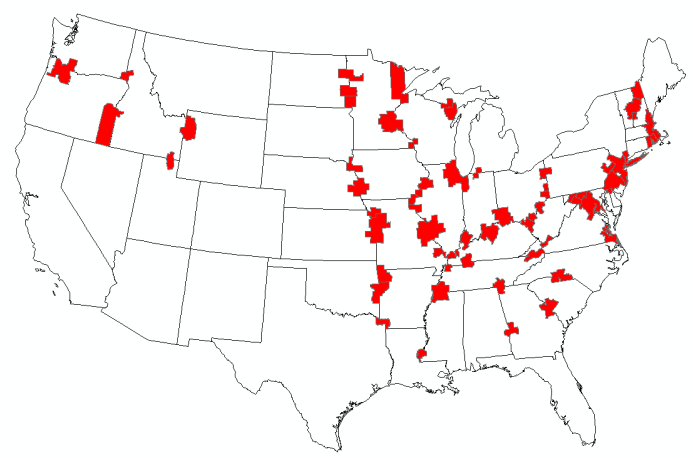

Figure 5: Area and Tax Rates
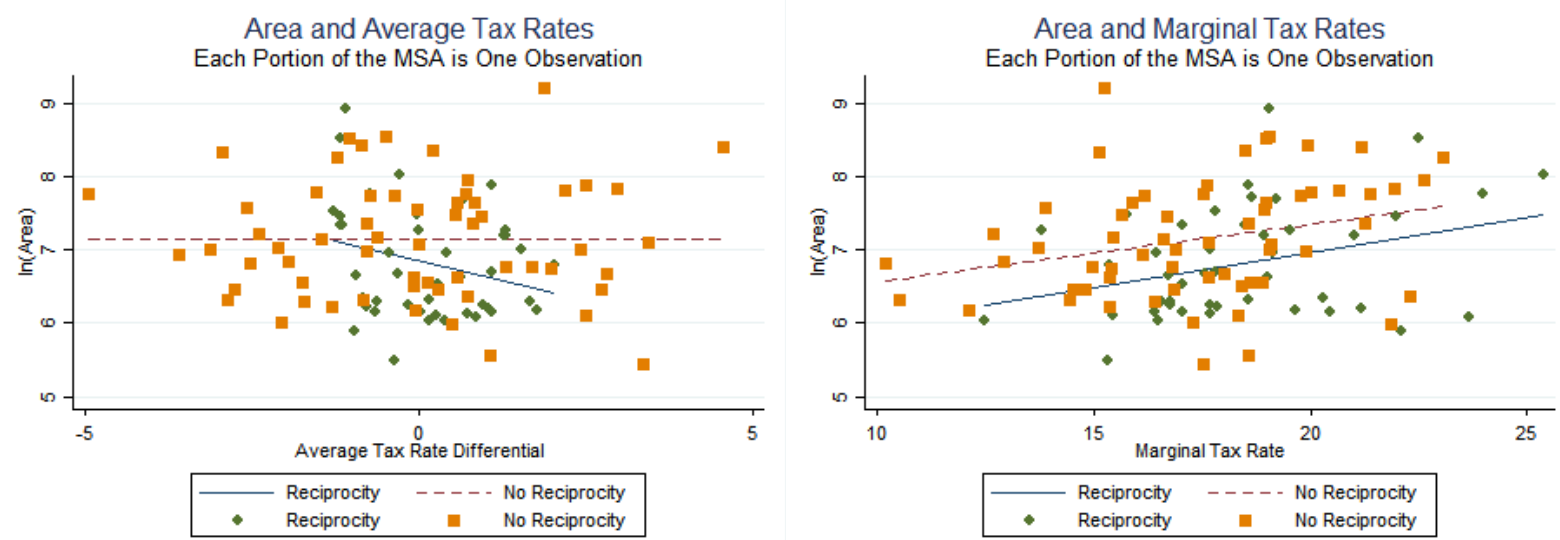

Figure 6: Perimeter and Tax Rates
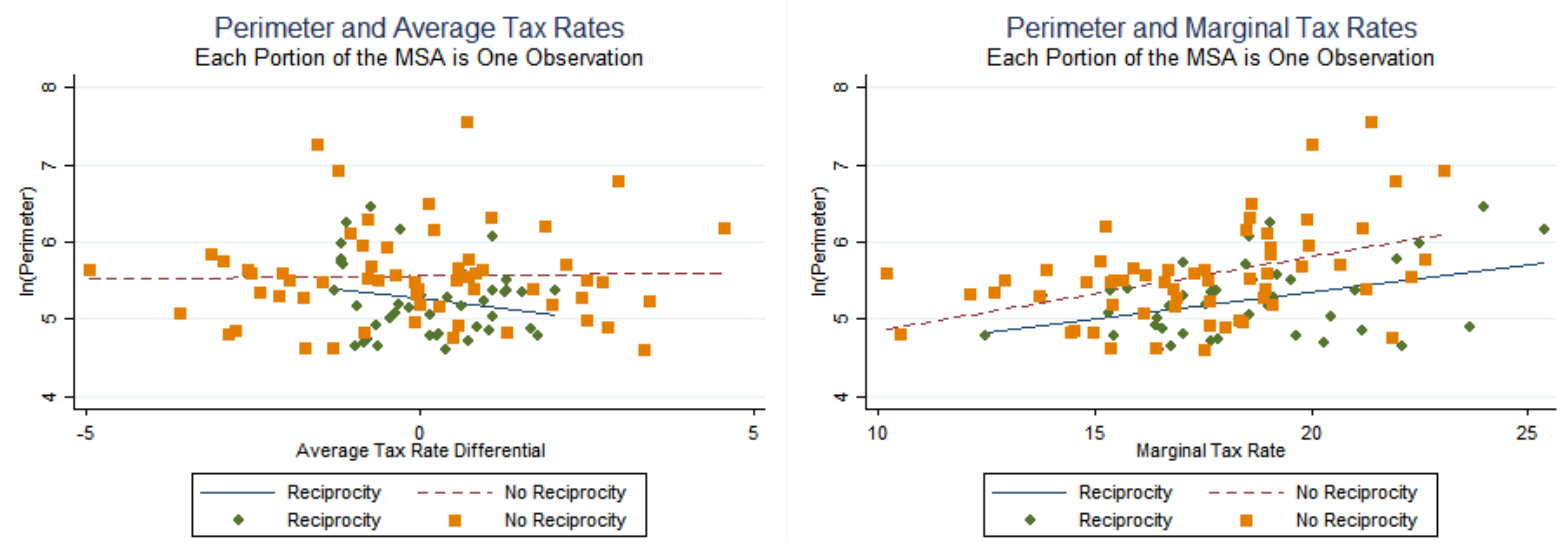
Figure 7: Commute Times Tax Rates
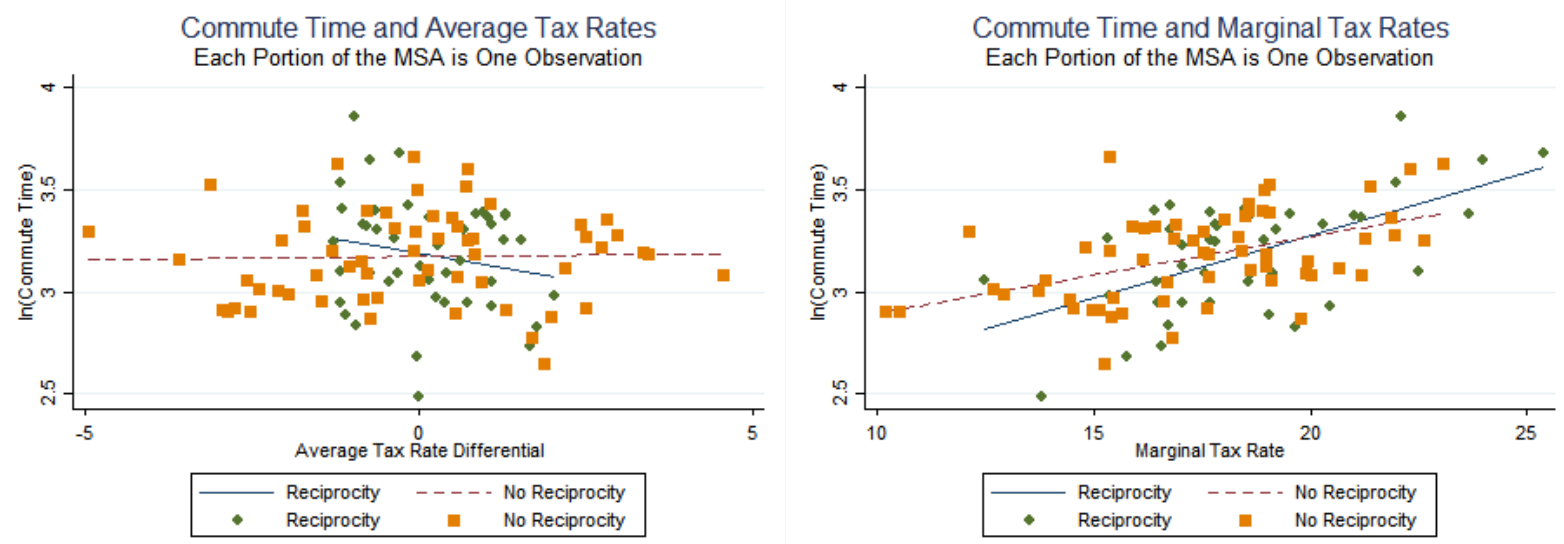

Table 1: Explaining Reciprocity

Panel A: State Level Regressions

\begin{tabular}{c|ccccc}
\hline & $(1)$ & $(2)$ & $(3)$ & $(4)$ & $(5)$ \\
\hline$m t r$ & 3.51 & & & & -4.42 \\
& $(2.11)$ & & & & $(5.34)$ \\
$a t r$ & & $4.72^{* *}$ & & & 9.95 \\
& & $(2.32)$ & & & $(6.43)$ \\
commute & & & .007 & & -.02 \\
time & & & $(.020)$ & & $(.02)$ \\
interstate & & & & 1.70 & 1.14 \\
commute & & & & $(1.28)$ & $(1.40)$ \\
\hline Number of & 51 & 51 & 51 & 51 & 51 \\
Observa- & & & & & \\
tions & & & & & \\
$R^{2}$ & .04 & .07 & .01 & .04 & .10 \\
\hline
\end{tabular}

The dependent variable is equal to one if the state has at least one reciprocity agreement. The independent variables are the total marginal tax rate, the total average tax rate, the average commute time, the fraction of workers with an interstate commute. All standard errors are robust ${ }^{* * *} 99 \%,{ }^{* *} 95 \%$, and $* 90 \%$.
Panel B: Border Pair Regressions

\begin{tabular}{c|ccccc}
\hline & $(1)$ & $(2)$ & $(3)$ & $(4)$ & $(5)$ \\
\hline$\Delta m t r$ & -3.03 & & & & -3.49 \\
& $(2.98)$ & & & & $(3.90)$ \\
$\Delta a t r$ & & -.72 & & & .28 \\
& & $(3.78)$ & & & $(4.67)$ \\
$\Delta$ commute time & & & .01 & & .02 \\
& & & $(.03)$ & & $(.03)$ \\
$\Delta$ interstate & & & & $3.23^{*}$ & $3.30^{*}$ \\
commute & & & & $(1.70)$ & $(1.70)$ \\
\hline Number of & 57 & 57 & 57 & 57 & 57 \\
Observations & & & & & \\
$R^{2}$ & .02 & .01 & .01 & .06 & .09
\end{tabular}

The dependent variable is equal to one if the state-border pair combination has a reciprocity agreement at the border. We only use state-border pairs included in our sample of analysis. The independent variables are the absolute value of the difference in: the marginal tax rates, the the average tax rates across the states, commute times and the interstate commutes. All standard errors are robust $* * * 99 \%, * * 95 \%$, and $* 90 \%$.

Table 2: Summary Statistics

\begin{tabular}{cccc} 
Variable & Full Sample & $R=0$ & $R=1$ \\
\hline Average Tax Rate & 7.44 & 7.06 & 8.29 \\
(Federal Plus State) & $(14.86)$ & $(15.33)$ & $(13.74)$ \\
Differential (Absolute & 1.62 & 1.83 & 1.62 \\
Value) & $(1.51)$ & $(1.62)$ & $(1.51)$ \\
Marginal Tax Rates & 19.33 & 19.01 & 20.04 \\
(Federal Plus State) & $(17.92)$ & $(18.31)$ & $(17.03)$ \\
Interstate Commute & .07 & .07 & .08 \\
& $(.26)$ & $(.26)$ & $(.28)$ \\
Commute Time & 28.07 & 28.07 & 27.87 \\
& $(27.24)$ & $(26.87)$ & $(28.06)$ \\
$\mathrm{N}$ & 888,017 & 599,535 & 288,482 \\
\hline
\end{tabular}

This table displays the summary statistics for the full sample and conditional on

being in a reciprocity or no reciprocity CBSA. Interstate commute averages are the average number of people in a household with an interstate commute. 
Table 3: Commute Time Results: Baseline Specification

\begin{tabular}{|c|c|c|c|c|c|c|c|c|c|}
\hline & $\begin{array}{l}(1) \\
\text { No Co }\end{array}$ & No Controls / Fixed Effects & $\begin{array}{r}(3) \\
\text { Affects }\end{array}$ & $(4)$ & $\begin{array}{c}(5) \\
\text { Fixed E }\end{array}$ & $(6)$ & $\begin{array}{l}(7) \\
\text { With }\end{array}$ & $\begin{array}{c}(8) \\
\text { d Effects }\end{array}$ & $\begin{array}{c}(9) \\
\text { Controls }\end{array}$ \\
\hline & $R=0$ & $R=1$ & Pooled & $R=0$ & $R=1$ & Pooled & $R=0$ & $R=1$ & Pooled \\
\hline$m t r$ & $.246^{* * *}$ & $271^{* * *}$ & $.246^{* * *}$ & $221^{* * *}$ & $.225^{* * *}$ & $.221^{* * *}$ & $.043^{* * *}$ & $.021^{* * *}$ & $.040^{* * *}$ \\
\hline & $(.030)$ & $(.048)$ & $(.029)$ & $(.022)$ & $(.025)$ & $(.021)$ & $(.006)$ & $(.003)$ & $(.011)$ \\
\hline$m t r * R$ & & & $\begin{array}{c}.025 \\
(.056)\end{array}$ & & & $\begin{array}{c}.004 \\
(.032)\end{array}$ & & & $\begin{array}{l}-.007 \\
(.016)\end{array}$ \\
\hline$\triangle a t r$ & $-.529^{* *}$ & -.343 & $-.529^{* *}$ & $-.360^{* *}$ & -.231 & $-.360 * *$ & .050 & -.062 & .073 \\
\hline & $(.241)$ & $(.420)$ & $(.239)$ & $(.156)$ & $(.261)$ & $(.155)$ & $(.072)$ & $(.031)$ & $(.078)$ \\
\hline$\triangle a t r * R$ & & & .185 & & & .131 & & & $-.251^{* *}$ \\
\hline & & & $(.479)$ & & & $(.301)$ & & & $(.115)$ \\
\hline Live in Central City & & & & & & & -.607 & .670 & .080 \\
\hline & & & & & & & $(1.070)$ & $(.755)$ & $(.825)$ \\
\hline Number of Observations & 599,535 & 288,482 & 888,017 & 599,535 & 288,482 & 888,017 & 599,535 & 288,482 & 888,017 \\
\hline$R^{2}$ & .028 & .028 & .029 & .059 & .072 & .063 & .253 & .268 & .255 \\
\hline CBSA Fixed Effects & $\mathrm{N}$ & $\mathrm{N}$ & $\mathrm{N}$ & $\mathrm{Y}$ & $\mathrm{Y}$ & $\mathrm{Y}$ & $\mathrm{Y}$ & $\mathrm{Y}$ & $\mathrm{Y}$ \\
\hline Year Fixed Effect & $\mathrm{N}$ & $\mathrm{N}$ & $\mathrm{N}$ & $\mathrm{Y}$ & $\mathrm{Y}$ & Y & $\mathrm{Y}$ & Y & Y \\
\hline Industry Fixed Effects & $\mathrm{N}$ & $\mathrm{N}$ & $\mathrm{N}$ & $\mathrm{N}$ & $\mathrm{N}$ & $\mathrm{N}$ & $\mathrm{Y}$ & Y & $\mathrm{Y}$ \\
\hline Household Controls & $\mathrm{N}$ & $\mathrm{N}$ & $\mathrm{N}$ & $\mathrm{N}$ & $\mathrm{N}$ & $\mathrm{N}$ & Y & Y & $\mathrm{Y}$ \\
\hline Policy Controls & $\mathrm{N}$ & $\mathrm{N}$ & $\mathrm{N}$ & $\mathrm{N}$ & $\mathrm{N}$ & $\mathrm{N}$ & Y & $\mathrm{Y}$ & $\mathrm{Y}$ \\
\hline Clustered SEs? & Y & Y & Y & Y & Y & Y & $\mathrm{Y}$ & $\mathrm{Y}$ & $\mathrm{Y}$ \\
\hline ACS Sample Weights? & Y & Y & $\mathrm{Y}$ & $\mathrm{Y}$ & $\mathrm{Y}$ & $\mathrm{Y}$ & Y & $\mathrm{Y}$ & $\mathrm{Y}$ \\
\hline
\end{tabular}

The table presents the results of equation 16 where the dependent variable is the total commute time of the household and the average tax

differential is defined in the text. Columns (1)-(3) include only the tax variables and an intercept term. Columns (4)-(6) add CBSA and year dummies. Columns (7)-(9) add the controls listed in the appendix. The dependent variable is the household commute time, the variable $R$ is one when the CBSA has a reciprocity agreement in place, $m t r$ is the marginal tax rate paid, and $\triangle a t r$ is the average tax rate in the state of residence minus the counter-factual average tax rate. All standard errors are clustered at the CBSA level. $* * * 99 \%,{ }^{* *} 95 \%$, and $* 90 \%$.

Table 4: Commute Time Results: Heterogeneity by Income and Homeownership

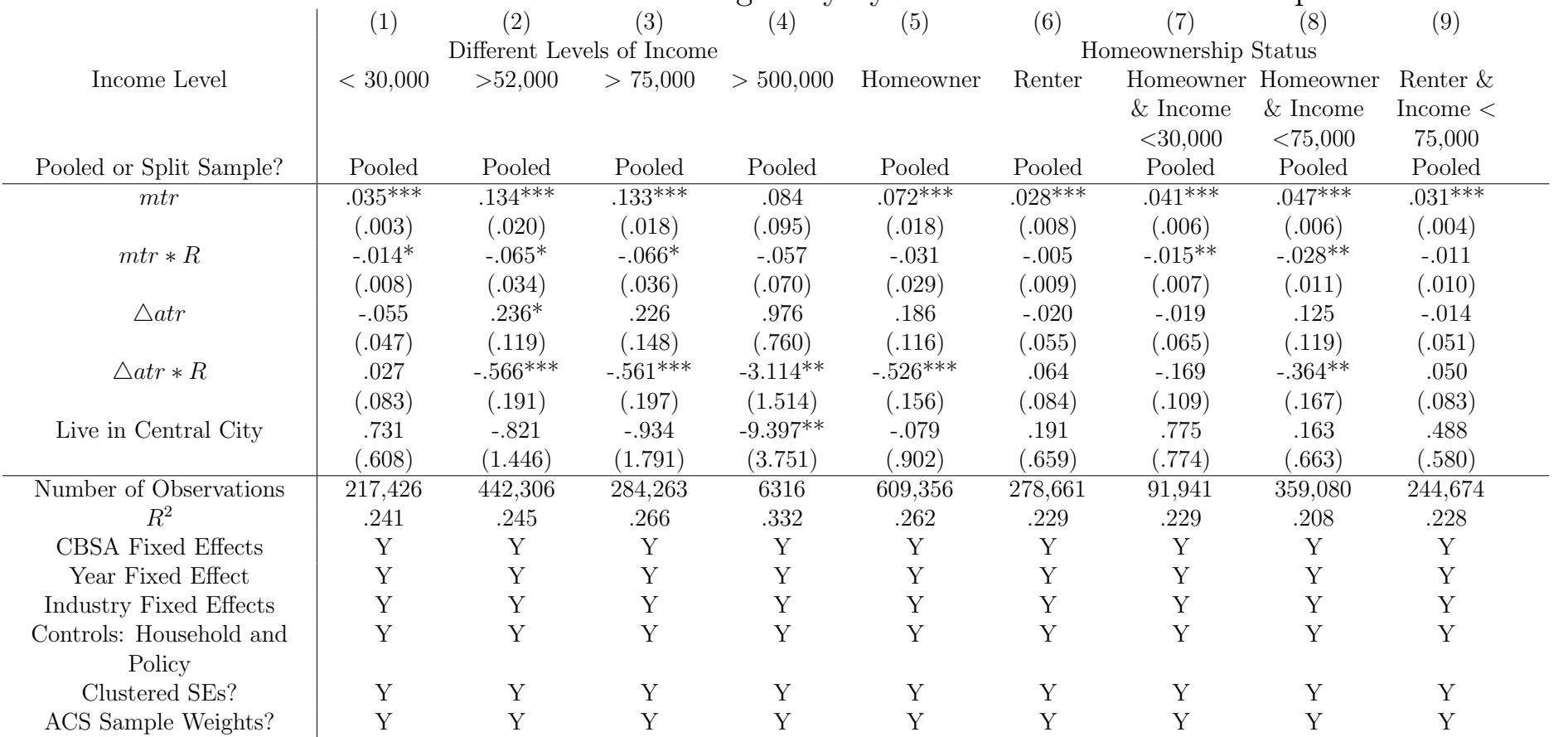

The table cuts the sample by income. The first column uses only households in the bottom quartile of the income distribution. Column (2) uses households who are above the median household income. Column (3) uses households above the mean household income. The fourth column uses households with incomes above 500,000. Columns (5) and (6) focus on homeowners and renters, respectively. Columns (7)-(9) look at lower income

households by homeownership status. The dependent variable is the household commute time, the variable $R$ is one when the CBSA has a reciprocity agreement in place, $m t r$ is the marginal tax rate paid, and $\triangle a t r$ is the average tax rate in the state of residence minus the counter-factual average tax rate. All standard errors are clustered at the CBSA level. ***99\%, ** $95 \%$, and *90\%. 
Table 5: Commute Time Results: Heterogeneity from Geography

\begin{tabular}{|c|c|c|c|c|c|c|}
\hline \multirow{5}{*}{ Specific Restriction } & \multicolumn{2}{|c|}{ River Borders } & $(3)$ & \multicolumn{2}{|c|}{ Wharton Regulation Index } & (6) \\
\hline & Rivers & Non-Rivers & Least & Most & Least & Most \\
\hline & & & Restrictive & Restrictive & Restrictive & Restrictive \\
\hline & & & Zoning & Zoning & Zoning \& & Zoning \& \\
\hline & & & & & Income $>$ & Income $>$ \\
\hline Pooled or Split Sample? & Pooled & Pooled & Pooled & Pooled & $\begin{array}{l}75,000 \\
\text { Pooled }\end{array}$ & $\begin{array}{l}75,000 \\
\text { Pooled }\end{array}$ \\
\hline$m t r$ & .012 & $.044^{* * *}$ & .017 & .023 & -.068 & $.116^{* *}$ \\
\hline & $(.012)$ & $(.007)$ & $(.011)$ & $(.021)$ & $(.088)$ & $(.040)$ \\
\hline$m t r * R$ & .019 & $-.042 * * *$ & -.016 & .001 & .131 & .007 \\
\hline & $(.019)$ & $(.014)$ & $(.026)$ & $(.026)$ & $(.11)$ & $(.036)$ \\
\hline$\triangle a t r$ & $.246^{*}$ & -.055 & $.228^{*}$ & -.047 & .217 & -.167 \\
\hline & $(.145)$ & $(.059)$ & $(.122)$ & $(.164)$ & $(.272)$ & $(.207)$ \\
\hline$\triangle a t r * R$ & $-.330^{* *}$ & -.156 & $-.306^{*}$ & .355 & $-.794^{* *}$ & .186 \\
\hline & $(.148)$ & $(.186)$ & $(.166)$ & $(.204)$ & $(.289)$ & $(.428)$ \\
\hline Live in Central City & .144 & -.147 & .233 & -2.343 & 3.704 & -3.224 \\
\hline & $(.543)$ & $(1.254)$ & $(1.471)$ & $(2.348)$ & $(4.600)$ & $(3.322)$ \\
\hline Number of Observations & 421,510 & 466,507 & 52,697 & 137,465 & 4890 & 47,858 \\
\hline$R^{2}$ & .261 & .255 & .220 & .239 & .243 & .248 \\
\hline CBSA \& Year Fixed Effects & Y & $\mathrm{Y}$ & $\mathrm{Y}$ & $\mathrm{Y}$ & $\mathrm{Y}$ & $\mathrm{Y}$ \\
\hline Industry Fixed Effects & $\mathrm{Y}$ & $\mathrm{Y}$ & $\mathrm{Y}$ & Y & $\mathrm{Y}$ & $\mathrm{Y}$ \\
\hline Controls: $\mathrm{HH}$ and Policy & $\mathrm{Y}$ & Y & $\mathrm{Y}$ & Y & $\mathrm{Y}$ & Y \\
\hline
\end{tabular}

The table cuts the sample by different geographic restrictions. The first column uses only cities where the border is a river.

Column (2) uses cities where the border is partly linear. The remaining columns cut the sample based on the Gyourko, Saiz and Summers (2008) zoning regulation index. Column (3) uses only observations in the quartile of the least restrictive zoning index. The fourth column uses cities with the most restrictive zoning index. The last two columns focus on high income earners in the least restrictive and most restrictive cities, respectively. The dependent variable is the household commute time, the variable $R$ is one when the CBSA has a reciprocity agreement in place, $m t r$ is the marginal tax rate paid, and $\triangle a t r$ is the average tax rate in the state of residence minus the counter-factual average tax rate. All standard errors are clustered at the CBSA level and all regressions use ACS household weights. ***99\%, **95\%, and ${ }^{*} 90 \%$.

\begin{tabular}{|c|c|c|c|c|c|c|c|}
\hline \multirow[b]{2}{*}{ Specific Model } & \multicolumn{4}{|c|}{ IV Results } & \multicolumn{3}{|c|}{ Equal MSA Weighting } \\
\hline & IV & IV & $\begin{array}{l}\text { IV - high } \\
\text { income }\end{array}$ & $\begin{array}{l}\text { IV - high } \\
\text { income }\end{array}$ & OLS & OLS & OLS \\
\hline Pooled or Split Sample? & $R=0$ & $R=1$ & $R=0$ & $R=1$ & $R=0$ & $R=1$ & Pooled \\
\hline$m t r$ & $\begin{array}{c}.038^{* * * *} \\
(.004)\end{array}$ & $\begin{array}{c}.019^{* * *} \\
(.003)\end{array}$ & $\begin{array}{c}.123^{* * *} \\
(.013)\end{array}$ & $\begin{array}{c}.078^{* * *} \\
(.018)\end{array}$ & $\begin{array}{c}.031^{* * *} \\
(.007)\end{array}$ & $\begin{array}{c}.025^{* * *} \\
(.005)\end{array}$ & $\begin{array}{l}.022^{* *} \\
(.009)\end{array}$ \\
\hline$m t r * R$ & & & & & & & $\begin{array}{c}.017 \\
(.016)\end{array}$ \\
\hline$\triangle a t r$ & $.381^{* *}$ & -.155 & .311 & -.682 & $.192^{* *}$ & $-.132^{*}$ & $.187^{*}$ \\
\hline & $(.188)$ & $(.189)$ & $(.204)$ & $(.509)$ & $(.091)$ & $(.076)$ & $(.097)$ \\
\hline$\triangle a t r * R$ & & & & & & & $\begin{array}{c}-.337^{* *} \\
(.148)\end{array}$ \\
\hline Live in Central City & -.672 & .776 & -2.686 & 1.395 & -.168 & -.387 & -.082 \\
\hline & $(1.058)$ & $(.727)$ & $(2.170)$ & $(1.203)$ & $(.997)$ & $(1.018)$ & $(.598)$ \\
\hline Number of Observations & 599,535 & 288,482 & 187,233 & 97,030 & 599,535 & 288,482 & 888,017 \\
\hline$R^{2}$ & .252 & .268 & .270 & .271 & .213 & .233 & .221 \\
\hline F-Statistic & 16.932 & 49.442 & 20.172 & 10.236 & - & - & - \\
\hline First Stage Coefficient & $.370^{* * *}$ & $.133^{* * *}$ & $.490^{* * *}$ & $.154^{* * *}$ & - & - & - \\
\hline & $(.090)$ & $(.019)$ & $(.109)$ & $(.048)$ & & & \\
\hline CBSA \& Year Fixed Effects & $\mathrm{Y}$ & $\mathrm{Y}$ & $\mathrm{Y}$ & $\mathrm{Y}$ & Y & Y & Y \\
\hline Industry Fixed Effects & $\mathrm{Y}$ & $\mathrm{Y}$ & $\mathrm{Y}$ & $\mathrm{Y}$ & Y & Y & Y \\
\hline Controls: HH and Policy & Y & Y & Y & Y & Y & Y & Y \\
\hline
\end{tabular}

Columns (1)-(4) use the difference in the own marginal tax rate and counter-factual marginal tax rate as an instrument for the average tax rate differential. The first two columns use the full sample and the next two columns use only households with an income greater than the mean income in the sample. The last three columns weight each observation such that each CBSA is given equal weight in the sample; the estimation of these regressions are by OLS. The dependent variable is the household commute time, the variable $R$ is one when the CBSA has a reciprocity agreement in place, $m t r$ is the marginal tax rate paid, and $\triangle a t r$ is the average tax rate in the state of residence minus the counter-factual average tax rate. All standard errors are clustered at the CBSA level. $* * * 99 \%, * * 95 \%$, and $* 90 \%$. 


\section{A Appendix (Online Only)}

\section{A.1 Derivation of Proposition 1}

In addition to the equal utility conditions, (1) - (3), another equal utility condition,

$$
V\left(w^{i}-c r_{T}^{i}-T^{i} p^{*}\right)=V\left(w^{i}-c r-T^{i} p^{i}(i)\right), i=1,2
$$

implies equal utility for all residents of the same state in the MSA. Then differentiating (A.1) with respect to $r_{T}^{i}$ for $i=1,2$ for the respective states in the MSA and solving for $\frac{d p^{i}(r)}{d r_{T}^{i}}$ gives

$$
\frac{d p^{i}(r)}{d r_{T}^{i}}=\frac{c}{l\left(p^{i}(r)\right)}=c N^{i}\left(p^{i}(r)\right)>0, i=1,2
$$

the rent gradient throughout the state. Differentiating (A.1) with respect to $r$ gives

$$
\frac{d p^{i}(r)}{d r}=-\frac{c}{l\left(p^{i}(r)\right)}, i=1,2
$$

Two lemmas will be useful in deriving Propositions 1 and 2:

Lemma 1. Each combination of $\left(w_{1}, w_{2}, E_{1}, E_{2}\right)$ is unique, that is, any value of $w_{1}$ uniquely determines the values of $\left(w_{2}, E_{1}, E_{2}\right)$.

Any wage rate, $w_{1}$ is associated with a unique level of employment in state $1, E_{1}$ given by $w_{1}=f_{1}^{\prime}\left(E_{1}\right)$. Then as the level employment in state 1 determines the level in state 2 $\left(E_{2}=N-E_{1}\right)$, the wage in state 2 is also determined by $E_{1}, w_{2}=f_{2}^{\prime}\left(N-E_{1}\right)$.

Lemma 2. Each combination $\left(r_{T}^{1}, r_{T}^{2}, N^{1}, N^{2}\right)$ is unique, that is, any value of $r_{T}^{1}$ uniquely determines the values of $\left(r_{T}^{2}, N^{1}, N^{2}\right)$.

From (A.2) and (A.3) it follows that given $r_{T}^{1}$ land rent, $p^{1}(r)$ at any $r$ in state 1 is determined. Then the population at each $r, N^{1}(r)$, is also determined as the total population in state $1, N^{1}$. Then this determines the total population of state 2 and the terminus, $r_{T}^{2}$, is determined by the condition that the demand for land equals the supply of land or $\int_{0}^{r_{T}^{2}} N^{2}(r) d r=r_{T}^{2}$ with the requirement that the land rent gradients in state 2 are defined by (A.2) and (A.3).

Then differentiating (1) with respect to $T^{1}$ gives

$$
\frac{d w^{1}}{d T^{1}}-c \frac{d r_{T}^{1}}{d T^{1}}-1=\frac{d w^{2}}{d T^{1}}-c \frac{d r_{T}^{2}}{d T^{1}}
$$


When states have reciprocity, another relationship between the wages in the two states and the change in the tax rate in state 1 can be found by differentiating (2) to obtain

$$
\frac{d w^{1}}{d T^{1}}-\frac{d w^{2}}{d T^{1}}=0
$$

where if there is to be an equal change in wage rates in the two states then by Lemma 1 it must be the case that neither wage changes. For the case of no reciprocity differentiating (3) gives

$$
\frac{d w^{1}}{d T^{1}}-1=\frac{d w^{2}}{d T^{1}}
$$

Equations (A.5) and (A.6) show, respectively, that in the case of MSAs with reciprocity, the tax differential is not capitalized into wages and in the case of MSAs without reciprocity it is fully capitalized into wages. Then using (A.5) in (A.4) gives

$$
\frac{d r_{T}^{2}}{d T^{1}}=\frac{1}{c}+\frac{d r_{T}^{1}}{d T^{1}}
$$

for the case with reciprocity. When there is no reciprocity between the two states, using (A.6) in (A.4) gives

$$
\frac{d r_{T}^{2}}{d T^{1}}=\frac{d r_{T}^{1}}{d T^{1}}=0
$$

where if there is to be an equal change in the termini by Lemma 2 it must equal zero. Differentiating the labor market equilibrium conditions (4) establishes the relationship between changes in wages and employment in the two states that occur as a result of the increase in taxes in state 1 . Then, differentiating (4) gives

$$
\begin{gathered}
f_{1} "\left(\left(N_{T}^{1}+\int_{0}^{r_{T}^{1}} \frac{d N^{1}(r)}{d r_{T}^{1}} d r\right) \frac{d r_{T}^{1}}{T^{1}}+\left(\int_{0}^{\widetilde{r}^{2}} \frac{d N^{2}(r)}{d r_{T}^{2}} d r\right) \frac{d r_{T}^{2}}{T^{1}}+N_{\widetilde{r}^{2}} \frac{d \widetilde{r}^{2}}{T^{1}}\right)=\frac{d w^{1}}{d T^{1}}=0 \\
\text { and } \\
f_{2} "\left(\left(N_{T}^{2}+\int_{\widetilde{r}^{2}}^{r_{T}^{2}} \frac{d N^{2}(r)}{d r_{T}^{2}} d r\right) \frac{d r_{T}^{2}}{T^{1}}-N_{\widetilde{r}^{2}} \frac{d \widetilde{r}^{2}}{T^{1}}\right)=\frac{d w^{2}}{d T^{1}}=0
\end{gathered}
$$

where $N_{T}^{i} \equiv N\left(p^{*}\right), i=1,2$, the population near the terminus of the state and $N_{\widetilde{r}^{2}} \equiv$ $N\left(p^{2}(\widetilde{r})\right)$, the population at the fringe of those commuting from state 2 to 1 . Next, we can consider the impact of the tax increase on the equilibrium population distribution between the two states. Then, differentiating the population clearing condition $\int_{0}^{r_{T}^{1}} N^{1}(r) d r+$ $\int_{0}^{r_{T}^{2}} N^{2}(r) d r=N$ yields

$$
\left[N_{T}^{1}+\int_{0}^{r_{T}^{1}} \frac{d N^{1}(r)}{d r_{T}^{1}} d r\right] \frac{d r_{T}^{1}}{d T^{1}}+\left[N_{T}^{2}+\int_{0}^{r_{T}^{2}} \frac{d N^{2}(r)}{d r_{T}^{2}} d r\right] \frac{d r_{T}^{2}}{d T^{1}}=0
$$


Both bracketed terms are positive and denoted by $\frac{d N^{i}}{d r_{T}^{i}}$. Then solving (A.9) and (A.10) gives (6) and (7).

In the case in which there is no reciprocity, differentiating (4) and applying (A.8) gives

$$
f_{1} "\left(N_{\widetilde{r}^{2}} \frac{d \widetilde{r}^{2}}{T^{1}}\right)=\frac{d w^{1}}{d T^{1}} \text { and }-f_{2} "\left(-N_{\widetilde{r}^{2}} \frac{d \widetilde{r}^{2}}{T^{1}}\right)=\frac{d w^{2}}{d T^{1}}
$$

Then solving (A.11) and (A.6) gives (9) and (10).

\section{A.2 Derivation of Corollary 1}

In MSAs with reciprocity, from (A.2) and (6) it follows that the decrease in $r_{T}^{1}$ will decrease land rents throughout the state (b), decreasing the population density $(c)$ and therefore the total population in state 1 (a). From (A.5) there is no change in the net wage and therefore the employment in state 1 will not change $(d)$ and $(e)$. The same reasoning applies for the impacts in state 2 .

In MSAs with no reciprocity, as neither termini changes (A.8) then neither land rents nor population are affected by the tax increase as both are determined by $r_{T}^{1}(a)$, (b) and (c). From (9) wages in state 1 increase and wages in state 2 decrease (d) and it follows that employment in state 2 must increase and employment in state 1 decreases $(e)$.

\section{A.3 Derivation of the Impact of a Tax Increase on the Population Gradient $\left(\frac{d N^{i}(r)}{d T^{1}}\right)$}

As seen in Proposition 2 to be able to sign the impact of an increase in the the tax rate on average commuting times requires determining how the population gradient changes with an increase in $T^{1}, \frac{d N^{i}(r)}{d T^{1}}$. Recall that $N^{i}(r)=\frac{1}{l\left(p^{i}(r)\right)}$. Then differentiating with respect to $T^{1}$ yields

$$
\frac{d N^{i}(r)}{d T^{1}}=-\frac{1}{l\left(p^{i}(r)\right)^{2}} \frac{\partial l\left(p^{i}(r)\right)}{\partial p^{i}(r)} \frac{d p^{i}(r)}{d r_{T}^{i}} \frac{d r_{T}^{i}}{d T^{1}}
$$

Then substituting for $\frac{d p^{i}(r)}{d r_{T}^{i}}$ using (A.2) gives

$$
\frac{d N^{i}(r)}{d T^{1}}=-\frac{1}{l\left(p^{i}(r)\right)^{2}} \frac{\partial l\left(p^{i}(r)\right)}{\partial p^{i}(r)} \frac{c}{l\left(p^{i}(r)\right)} \frac{d r_{T}^{i}}{d T^{1}}=-\frac{c}{l\left(p^{i}(r)\right)^{3}} \frac{\partial l\left(p^{i}(r)\right)}{\partial p^{i}(r)} \frac{d r_{T}^{i}}{d T^{1}}
$$

Then substituting $N^{i}(r)=\frac{1}{l\left(p^{i}(r)\right)}$ and $\varepsilon=-\frac{\partial l\left(p^{i}(r)\right)}{\partial p^{i}(r)} \frac{p^{i}(r)}{l\left(p^{i}(r)\right)}$ yields

$$
\frac{d N^{i}(r)}{d T^{1}}=c \varepsilon \frac{N^{i}(r)}{p^{i}(r) l\left(p^{i}(r)\right)} \frac{d r_{T}^{i}}{d T^{1}}
$$


or, in percentage terms, $N^{\hat{i}}(r)=\frac{\frac{d N^{i}(r)}{d r_{T}^{i}}}{N^{i}(r)}$,

$$
N^{i}(r)=\frac{c \varepsilon}{p^{i}(r) l\left(p^{i}(r)\right)}
$$

Then from (A.15) we can see that if $\varepsilon<1$, spending on land per household $\left(p^{i}(r) l\left(p^{i}(r)\right)\right)$ will be lower the further from the CBD (and the lower the $p^{i}(r)$ ) and therefore the percentage change in population will be greater; if $\varepsilon>1$ the reverse is true - spending on land per household will be greater the further away from the CBD and therefore the percentage change in population is smaller; and if $\varepsilon=1$ the percentage change in population is the same throughout the state.

\section{A.4 Derivation of Proposition 2}

Differentiating (11) with respect to $T^{1}$ gives

$$
\begin{gathered}
\frac{d A C^{1}}{d T^{1}}=\frac{N_{T}^{1}}{N^{1}}\left(c r_{T}^{1}-A C^{1}\right) \frac{d r_{T}^{1}}{d T^{1}}+\frac{1}{N^{1}}\left(\int_{0}^{r_{T}^{1}} N^{1}(r)\left(c r-A C^{1}\right) \hat{N}^{1}(r) d r\right) \frac{d r_{T}^{i}}{d T^{1}} \\
\quad \text { and } \\
\frac{d A C^{2}}{d T^{1}}=\frac{N_{T}^{2}}{N^{i}}\left(c r_{T}^{2}-A C^{2}\right) \frac{d r_{T}^{2}}{d T^{1}}+\frac{1}{N^{2}}\left(\int_{0}^{r_{T}^{2}} N^{2}(r)\left(c r-A C^{2}\right) \hat{N}^{2}(r) d r\right) \frac{d r_{T}^{2}}{d T^{1}}+\frac{N_{\widetilde{r}^{2}}}{N^{2}} S \frac{d \widetilde{r}^{2}}{d T^{1}} .
\end{gathered}
$$

where we substitute $N^{i}(r) \cdot \hat{N}^{i}(r)$ for $\frac{d N^{i}(r)}{d r_{T}^{i}}$.

Then as apparent in (A.16), for state 1, the impact of a tax increase on commuting times can be decomposed into two components. The first is the impact due to a change in the termini of the state. An expansion of the state's borders will increase average commute times as these commuters will have longer commutes than the average $\left(c r_{T}^{i}-A C^{i}>0\right)$. Then the sign of this term is simply the sign of $\frac{d r_{T}^{i}}{d T^{1}}$. The sign of the term $\left(\int_{0}^{r_{T}^{i}} N^{1}(r)\left(c r-A C^{i}\right) \hat{N^{i}}(r) d r\right)$ depends on how equilibrium changes in land prices in the state affect the distribution of the population - specifically, in percentage terms, are the increases in population greater nearer the CBD where commuting costs are less than the average cost $\left(A C^{i}\right)$ or near the fringe of the MSA where commuting costs are much higher. As shown in (A.3) if $\varepsilon=1$ then $N^{i}(r)$ is a constant and the term equals zero as $\int_{0}^{r_{T}^{i}} N^{i}(r) c r \hat{N}^{i}(r) d r=\int_{0}^{r_{T}^{i}} N^{i}(r) A C^{i} \hat{N}^{i}(r) d r$; if $\varepsilon<[>] 1, \hat{N}^{i}(r)$ increases (decreases) with $r$ and $\int_{0}^{r_{T}^{i}} N^{i}(r) c r \hat{N}^{i}(r) d r>[<] \int_{0}^{r_{T}^{i}} N^{i}(r) A C^{i} \hat{N}^{i}(r) d r$ making $\int_{0}^{r_{T}^{i}} N^{i}(r)\left(c r-A C^{i}\right) \hat{N}^{i}(r) d r$ positive [negative].

Then if $\varepsilon<1, \operatorname{sign}\left(\frac{d A C^{1}}{d T^{1}}\right)=\operatorname{sign}\left(\frac{d r_{T}^{1}}{d T^{1}}\right)$ and for the case with reciprocity $\operatorname{sign}\left(\frac{d A C^{2}}{d T^{1}}\right)=$ $\operatorname{sign}\left(\frac{d r_{T}^{2}}{d T^{1}}\right)$. Then when there are reciprocity agreements, it follows that as $\frac{d r_{T}^{1}}{d T^{1}}<0$ then 
$\frac{d A C^{1}}{d T^{1}}<0$ and as $\frac{d r_{T}^{2}}{d T^{1}}>0$ then $\frac{d A C^{2}}{d T^{1}}>0$. In the absence of reciprocity agreements, $\frac{d r_{T}^{1}}{d T^{1}}=$ $\frac{d r_{T}^{2}}{d T^{1}}=0$ and $\frac{d \widetilde{r^{2}}}{d T^{1}}<0$ so that $\frac{d A C^{1}}{d T^{1}}=0$ and $\frac{d A C^{2}}{d T^{1}}<0$.

\section{A.5 Derivation of Proposition 3}

As most of the results stated in Proposition 3 follow from our analysis of the case with identical individuals, we shall provide a brief sketch of the proof.

\section{The Case with Reciprocity}

An Increase in $T_{H}^{1}$

We can differentiate an equal utility condition at the termini, similar to (1) to obtain

$$
\frac{d w_{H}^{1}}{d T_{H}^{1}}-c \frac{d r_{T}^{1}}{d T_{H}^{1}}-1=\frac{d w^{2}}{d T_{H}^{1}}-c \frac{d r_{T}^{2}}{d T_{H}^{1}}
$$

and an equal utility condition for high-skilled commuters from state 2 to state 1 similar to (2) to obtain

$$
\frac{d w_{H}^{1}}{d T_{H}^{1}}-\frac{d w_{H}^{2}}{d T_{H}^{1}}=0
$$

where it follows from Lemma 1, that if the changes in wages are to be equal in both states then both must equal zero. Then it follows there will be no change in employment as well. Then, analogous to the case with one income group using (A.18) in (A.17) gives

$$
\frac{d r_{T}^{2}}{d T_{H}^{1}}=\frac{1}{c}+\frac{d r_{T}^{1}}{d T_{H}^{1}}
$$

Then from Lemma 2 it follows that if $\frac{d r_{T}^{2}}{d T_{H}^{1}}>\frac{d r_{T}^{1}}{d T_{H}^{1}}$ that $\frac{d r_{T}^{2}}{d T_{H}^{1}}>0$ and $\frac{d r_{T}^{1}}{d T_{H}^{1}}<0$. The impacts on commuting times for the high-skilled workers are analogous to the case with one income group and if $\varepsilon \leq 1$. The low-skilled workers are unaffected by the increase in $T_{H}^{1}$ as neither $T_{H}^{1}, r_{T}^{i}$, nor $w_{H}^{i}$ enter their equal-utility conditions.

\section{An Increase in $T_{L}^{1}$}

In this case, the high-skilled workers are unaffected as $T_{L}^{1}$ does not enter either of their equal-utility conditions. For low-skilled workers, differentiating (15) with respect to $T_{L}^{1}$ gives

$$
\frac{d w_{L}^{1}}{d T_{L}^{1}}-1-l_{L}\left(p^{1}\left(\hat{r}^{1}\right)\right) \frac{d p^{1}\left(\hat{r}^{1}\right)}{d T_{L}^{1}}=\frac{d w_{L}^{2}}{d T_{L}^{1}}-l_{L}\left(p^{2}\left(\hat{r}^{2}\right)\right) \frac{d p^{2}\left(\hat{r}^{2}\right)}{d T_{L}^{2}}
$$

Differentiating the equal utility condition for low-skilled workers commuting from state 2 to 
state 1 (analogous to (2)), gives

$$
\frac{d w_{L}^{1}}{d T_{L}^{1}}=\frac{d w_{L}^{2}}{d T_{L}^{1}}=0
$$

As with the effect of increase in $T_{H}^{1}$ on high-skilled workers, $T_{L}^{1}$ has no impact on wages in either state. Then for the impact is on land prices, using (A.21) in(A.20) we obtain

$$
\frac{d p^{2}\left(\hat{r}^{2}\right)}{d T_{L}^{2}}=\frac{l_{L}\left(p^{1}\left(\hat{r}^{1}\right)\right)}{l_{L}\left(p^{2}\left(\hat{r}^{2}\right)\right)} \frac{d p^{1}\left(\hat{r}^{1}\right)}{d T_{L}^{1}}+\frac{1}{l_{L}\left(p^{2}\left(\hat{r}^{2}\right)\right)} .
$$

Then differentiating the market clearing condition for low-skilled population in the MSA gives

$$
\int_{0}^{r^{1}} N_{L}^{1}(r) \frac{\hat{N}_{L}^{1}(r)}{p^{1}(r) l\left(p^{1}(r)\right)} d r\left[\frac{d p^{1}\left(\hat{r^{1}}\right)}{d T_{L}^{1}}\right]+\int_{0}^{r^{2}} N_{L}^{2}(r) \frac{\hat{N}_{L}^{2}(r)}{p^{2}(r) l\left(p^{2}(r)\right)} d r\left[\frac{d p^{2}\left(\hat{r^{2}}\right)}{d T_{L}^{2}}\right]=0
$$

where $\hat{N}_{L}^{i}(r)=\frac{d N_{L}^{i}(r)}{d p^{i}\left(\hat{r}^{i}\right)} / N_{L}^{i}(r)$, the percentage change in the population due to an increase in rent at location $r$. Then from $(\mathrm{A} .22)$ and (A.23) we obtain $\frac{d p^{1}\left(\hat{r}^{1}\right)}{d T_{L}^{1}}<0$ and $\frac{d p^{2}\left(\hat{r}^{2}\right)}{d T_{L}^{1}}>0$. It follows that the population of state 1 decreases and that of state 2 increases. As employment is unchanged (no change in wages) there is an increase in interstate commuters from state 2 to state 1 . If $\varepsilon<1$ then the percentage changes in population are greatest further from the CBD. Then assuming $\varepsilon<1$, average commute times in in state 1 fall and they rise in state 2.

\section{The Case in the Absence of Reciprocity}

An Increase in $T_{H}^{1}$

We can be briefer here as, again, the effects of the tax increase on high-skilled workers are analogous to the case with a single income class. As in that case, the distinction between reciprocity and non-reciprocity is the tax implication for interstate commuters. Differentiating an equal utility condition similar to (2) for them gives

$$
\frac{d w_{H}^{1}}{d T_{H}^{1}}-1=\frac{d w_{H}^{2}}{d T_{H}^{1}}
$$

Then (A.24) and (A.17) gives

$$
\frac{d r_{T}^{1}}{d T_{H}^{1}}=\frac{d r_{T}^{2}}{d T_{H}^{1}}=0
$$

where, again, Lemma 2 is applied to obtain no effect of the tax increase on the size of the MSA. Then, the population distribution of high-skilled workers in the MSA is unchanged. 
However as the wage rate in state 1 increases relative to state 2 , employment in state 1 decreases meaning fewer interstate commutes from state 2 to state 1 . Then while the highskilled workers in state 1 commute times are unaffected by the tax increase there is a reduction commute times for workers residing in state 2 as fewer undertake interstate commutes. Again, low-skilled workers are unaffected.

An Increase in $T_{L}^{1}$

Again, high-skilled workers are unaffected by the increase in $T_{L}^{1}$. Differentiating the equal-utility condition for low-skilled commuters gives

$$
\frac{d w_{L}^{1}}{d T_{L}^{1}}-1=\frac{d w_{L}^{2}}{d T_{L}^{1}}
$$

Then using (A.26) in (A.22) gives

$$
\frac{d p^{2}\left(\hat{r}^{2}\right)}{d T_{L}^{2}}=\frac{d p^{1}\left(\hat{r}^{1}\right)}{d T_{L}^{1}}=0 .
$$

No change in land prices at the termini for low-skilled workers means no change in land prices and, therefore, population in either state. However as the wage for low-skilled workers increases relative to high-skilled workers, there is a decrease in employment in state 1 and increase in state 2. Then for low-skilled workers in state 1 commuting times are unaffected; as employment in state 1 decreases there should be fewer interstate commuters from state 2 and state 1 reducing average commute times there.

\section{A.6 Data Cleaning}

We restrict the sample to households in the ACS that live in a Metropolitan or Micropolitan Statistical Area - known as a 2010 Combined Statistical Area (CBSA) - that crosses state lines. To ensure a focus on commuting we eliminate any households that report that they reside on a working farm and anyone living in institutional quarters; households not in the labor force (mostly seniors) are also excluded from the analysis. Households consisting of more than one family or unrelated adults are excluded as well to try to focus on a unit (family) that makes a joint location decision. Adults who are currently in school are also excluded. Then the unit of observation is a one person household or family household with the family household consisting of the household head and spouse if the spouse is present. As households in the ACS are identified by PUMA not CBSA, we need to match PUMAs with CBSAs. This is done using a program available from the Missouri Census Data Center. ${ }^{22}$

\footnotetext{
${ }^{22}$ For a description of the geographical matching program available from the Missouri Census Data Center, please see http://mcdc.missouri.edu/ .
} 
It should be noted that for some of the smaller CBSAs the PUMA extends beyond the defined borders of the CBSA that are based on counties and includes counties considered rural. The matching program from the Missouri Census Data Center reports the percentage of households in the PUMA that reside in each county in the PUMA. If the percentage of the population residing in counties in the PUMA that are also in the CBSA is extremely low $(10 \%)$ we exclude that PUMA from our analysis. In cases where the PUMAs cross into multiple CBSAs, we merge the CBSAs and are left with fifty-one areas that cross state lines.

To calculate tax rates across the MSAs we calculate the average tax payment and the marginal tax rate (federal and state) conditional on being in either state of the cross-border MSA using the NBER's TAXSIM program (Feenberg and Coutts 1993). Most of the data needed to calculate tax liability using TAXSIM is found in the IPUMS. However, there are few components that are unavailable. While IPUMS reports quite detailed information about income including pensions, interest, social security, and transfers in addition to earnings it does not include state income tax refunds or taxable capital gains income. These we simply omit from the calculation, but we use reported interest and business income as the basis of property income. IPUMS does report two major deductions for state income taxes, mortgage payments and property taxes though it does not report the amount of mortgage interest payments. In our calculations we simply treat the entire mortgage payment as interest; the key is we make the same assumptions in both states. We do not attempt to impute other state and local taxes that might be deductible. IPUMS does not report taxdeductible contributions. For these we follow the NBER practice of imputing charitable contributions. ${ }^{23}$ In some circumstances, a household's tax payment is negative because they are able to receive credits. In cases where an household has a very small amount of total income or has small losses, their average tax rate can be extremely negative or extremely positive (several thousand percent). We view this as observations driven by idiosyncratic shocks. To prevent the analysis from being driven by outliers, we winsorize the top and bottom half of one percent of this variable; the results are robust to simply excluding these observations from the data.

For three state MSAs, we define the MSA as having a reciprocity agreement if the two most populous regions of the MSA have a reciprocity agreement; again the only CBSA where population is significantly concentrated across three states is the DC metro area and Maryland, Virginia, and D.C. all have reciprocity agreements.

\footnotetext{
${ }^{23}$ We use the NBER formula of $\$ 100+2 \%$ of income used to calculate state tax rates for "representative"

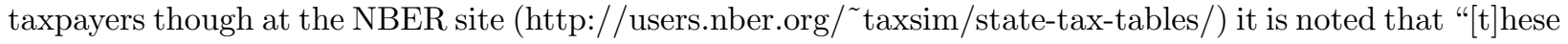
ratios are not intended to be typical or average, merely not unreasonable."
} 
Table A.1: Descriptive Statistics of CBSA's in Sample

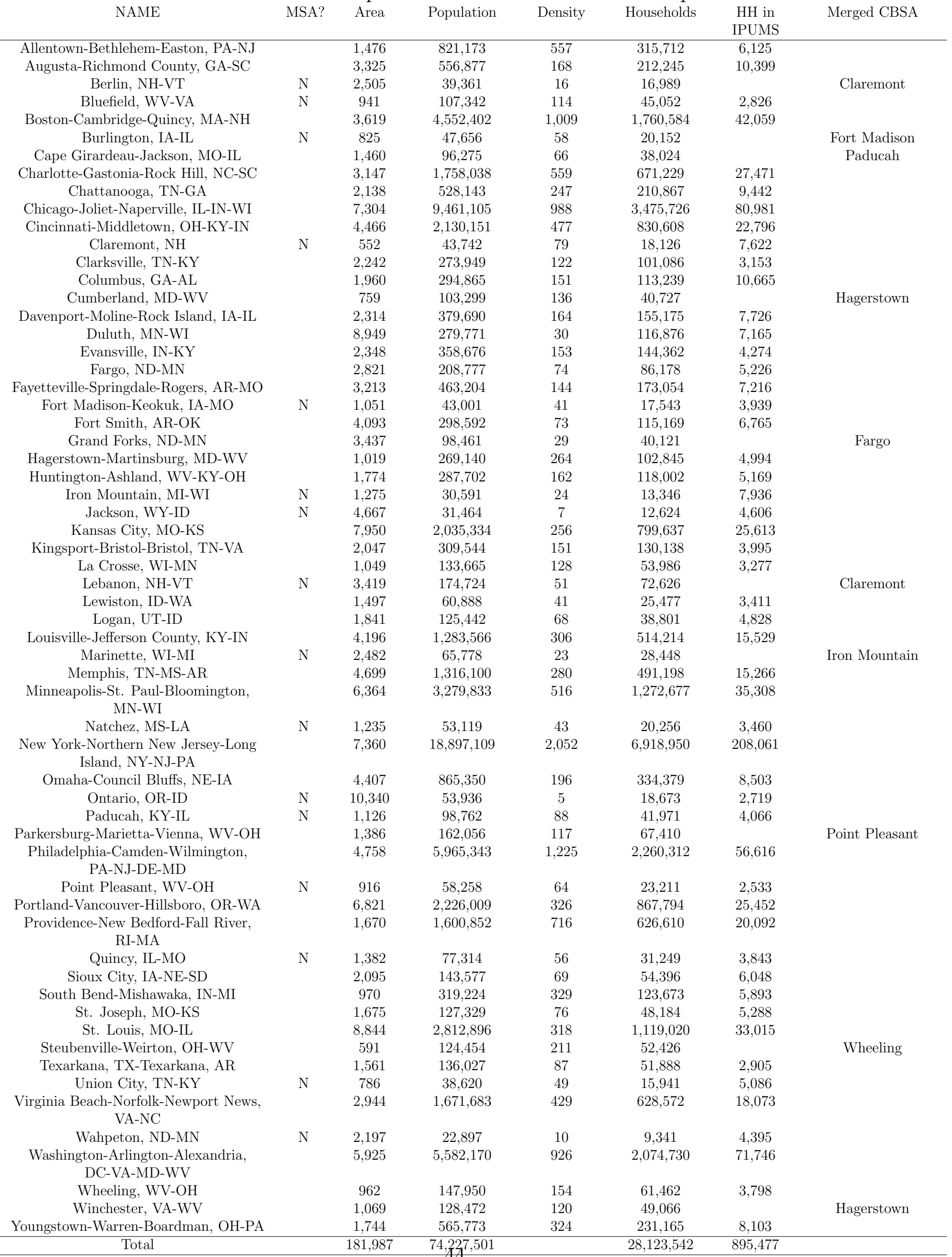

MSA? equals $\mathrm{N}$ if a micropolitan area. Area is measured in square miles. The last column indicated if the CBSA is merged with another CBSA because of over-lapping PUMAs. 


\section{A.7 List of Control Variables}

In addition to CBSA and time fixed effects, all regressions have the following control.

\section{Family-level Controls}

- Married

- Homeowner

- Number of children

- A cubic polynomial in total income.

- A dummy variable if the family lives in the state that the central city is located within.

- Mortgage payments (if homeowner).

- Rent payments (if a renter).

- Effective property tax rate.

Person-Specific Demographic Controls. All demographic control variables are included for person one. The same demographic control variables are included for person two, but interacted with a dummy variable for whether the household has two persons living in it.

- Education

- Race

- Gender

- Age

- Citizen

Person-Specific Economic Controls. All of these control control variables are included for person one. The same demographic control variables are included for person two, but interacted with a dummy variable for whether the household has two persons living in it.

- Work at home

- Drive to work using an automobile

- Work outside the MSA

- Work in the central city 
- A series of occupation dummies for finance, management, computers, science, community, legal, education, media, health, health support, protection, food, maintenance, sales, service, office, farming, construction, extraction, installation, production, transportation, military, home.

\section{State and Local Government Policies}

- Property tax rate (equal to property tax payments divided by the value of a house).

- Difference in gas tax rates.

- Difference in sales tax rates.

- The difference in state highway spending across the states.

- Per pupil education spending (local level aggregated to the particular state of residence).

- The log of school enrollment.

\section{A.8 A Non-linear ATR Specification}

In Table A.2 we relax the linearity of the response to the tax differentials and marginal tax rates by including a flexible third order polynomial in both of these terms. We then calculate the marginal effects at various points in the distribution of tax rates and differentials. In MSAs without reciprocity, higher marginal tax rates are associated with longer commutes. Various levels of atr differentials are statistically indistinguishable from each other. This is a nice verification that the linear parametrization performs quite well. Thus, we proceed with the linear specification in the text.

\section{A.9 Recent Movers}

In Table A.3 we again search for an asymmetric response to test for whether the effects are strongest for recent movers relative to households that have lived in the same place many years. We hypothesize that although (theoretically) households can change their place of residence or job each year based on tax policy changes, because of frictions households who optimally made a location choice twenty years ago should be less likely to have a discernible effect of tax rates on commutes. Over the past twenty years, state income tax codes have undergone many changes and a location decision that was optimal on the basis of taxes then may no longer be optimal. However, for recent movers, these households should have 
Table A.2: Commute Time Results: Size of Tax Differential

\begin{tabular}{|c|c|c|}
\hline & $\begin{array}{c}(1) \\
R=0\end{array}$ & $\begin{array}{c}(2) \\
R=1\end{array}$ \\
\hline \multirow[t]{2}{*}{$m t r:$ mean derivative } & $.079^{* * *}$ & .013 \\
\hline & $(.016)$ & $(.008)$ \\
\hline \multirow[t]{2}{*}{$m t r:$ at $m t r=10$} & $.060 * * *$ & $.041^{* * *}$ \\
\hline & $(.008)$ & $(.007)$ \\
\hline \multirow[t]{2}{*}{$m t r:$ at $m t r=30$} & $.097 * * *$ & .003 \\
\hline & $(.021)$ & $(.011)$ \\
\hline \multirow[t]{2}{*}{$\triangle a t r:$ mean derivative } & .047 & -.113 \\
\hline & $(.078)$ & $(.107)$ \\
\hline \multirow[t]{2}{*}{$\triangle a t r:$ at $\triangle a t r=-2$} & .043 & -.138 \\
\hline & $(.115)$ & $(.091)$ \\
\hline \multirow[t]{2}{*}{$\triangle a t r:$ at $\triangle a t r=2$} & .056 & -.049 \\
\hline & $(.110)$ & $(.149)$ \\
\hline \multirow{2}{*}{$\begin{array}{c}\text { Number of Observations } \\
R^{2}\end{array}$} & 599,535 & 288,482 \\
\hline & .253 & .267 \\
\hline CBSA Fixed Effects & $\mathrm{Y}$ & $\mathrm{Y}$ \\
\hline Year Fixed Effect & $\mathrm{Y}$ & $\mathrm{Y}$ \\
\hline Industry Fixed Effects & $\mathrm{Y}$ & $\mathrm{Y}$ \\
\hline $\begin{array}{c}\text { Controls: Household and } \\
\text { Policy }\end{array}$ & $\mathrm{Y}$ & $\mathrm{Y}$ \\
\hline Clustered SEs? & $\mathrm{Y}$ & $\mathrm{Y}$ \\
\hline ACS Sample Weights? & $\mathrm{Y}$ & $\mathrm{Y}$ \\
\hline
\end{tabular}

This table estimates the baseline expression (full sample) where $m t r$ and $\triangle a t r$ enter as a cubic function. Each cell reports the marginal effects. The first row is the mean derivative. The second two rows are the marginal effects evaluated at a particular point. The dependent variable is the household commute time, the variable $R$ is one when the CBSA has a reciprocity agreement in place, $m t r$ is the marginal tax rate paid, and $\triangle a t r$ is the average tax rate in the state of residence minus the counter-factual average tax rate. All standard errors are clustered at the CBSA level. $* * * 99 \%, * * 95 \%$, and $* 90 \%$. 
made their location decisions on the basis of the most recent tax policies and therefore, we expect these households to be most sensitive to tax differentials. We focus on high income households in this table given that the previous table shows it is these households who are most sensitive to atr differentials.

When looking at the effect of marginal tax rates, we unexpectedly see that for recent high-income movers, the marginal tax rates are associated with negative effects on commute times. However, the effect of the average tax rate differentials are of the expected sign and extremely large. In MSAs with reciprocity, a one percentage point in the tax differential changes commute times by about four minutes. This suggest that for recent movers to the area, the residence and job location decisions are strongly determined on the basis of the average tax differential, but that the marginal tax rate has a smaller effect. Comparing the coefficients of the the average tax rate differential, the effect is extremely large relative to non-movers in MSAs with reciprocity. It is reassuring that almost nothing is significant for superstar households that have not moved in more than twenty years. For households that moved more than ten years ago some variables remain significant and the effects in no reciprocity states are similar for recent movers and for non-movers. Despite changes in the tax system, even for households who have not moved in ten years, the tax differentials are of the expected sign. This could be a result of two reasons: (1) households that had large tax shocks away from their optimal location and place of work have already moved and the residents who stay are likely the residents who are still close to their optimum even under a new tax structure or (2) the tax system changes may be relatively small and exhibit path dependence (Bleakley and Lin 2012).

\section{A.10 Additional Robustness Checks}

In this sub-section we shift our focus to address certain econometric concerns. First, the reader may worry about measurement error in the tax rates given that we simulate them (using possibly top coded) data. Although use of TAXSIM is standard, we address this concern by relying on a dummy variable approach rather than an approach that uses the actual size of the tax differential. Under this approach $H$ takes on a value of one if the counter-factual tax rate is less than the own state tax rate and zero otherwise. Although measurement error may result us in coding the dummy variable incorrectly, this will only be the case for tax differentials where the tax rate and the counter-factual tax rate are extremely similar. Thus, the dummy variable approach will reduce measurement error concerns especially for high income households where tax differentials are likely large across states. Second, the dummy variable approach will allow us to study the effects of tax differentials 
Table A.3: Commute Time Results: Robustness

\begin{tabular}{|c|c|c|c|c|}
\hline \multirow{4}{*}{ Specific Restriction } & \multicolumn{2}{|c|}{ Recent Movers } & \multicolumn{2}{|c|}{ Not Recent Movers } \\
\hline & Moved & Moved & Moved & Moved \\
\hline & Last Year & Last Two & Over 10 & Over 20 \\
\hline & & Years & Years Ago & Years Ago \\
\hline Pooled or Split Sample? & Pooled & Pooled & Pooled & Pooled \\
\hline$m t r$ & $-1.090^{* * *}$ & $-.744^{* * *}$ & $.294^{* *}$ & .241 \\
\hline & $(.169)$ & $(.136)$ & $(.117)$ & $(.273)$ \\
\hline$m t r * R$ & $-1.145^{* *}$ & -.199 & .102 & .427 \\
\hline & $(.527)$ & $(.346)$ & $(.232)$ & $(.384)$ \\
\hline$\triangle a t r$ & $2.982^{* *}$ & $3.237^{* *}$ & $2.844^{* * *}$ & $2.708^{* * *}$ \\
\hline & $(1.290)$ & $(1.418)$ & $(.683)$ & $(.678)$ \\
\hline$\triangle a t r * R$ & $-7.425^{* *}$ & $-7.020^{* *}$ & $-3.876^{* *}$ & -.7693 \\
\hline & $(2.777)$ & $(3.422)$ & $(1.500)$ & $(2.093)$ \\
\hline Live in Central City & $-27.691 * *$ & $-17.591^{* * *}$ & $-12.313^{* *}$ & -7.014 \\
\hline & $(10.67)$ & $(3.952)$ & $(4.833)$ & $(11.000)$ \\
\hline Number of Observations & 469 & 853 & 2674 & 978 \\
\hline$R^{2}$ & 419 & .369 & .368 & .366 \\
\hline CBSA Fixed Effects & $\mathrm{Y}$ & $\mathrm{Y}$ & $\mathrm{Y}$ & $\mathrm{Y}$ \\
\hline Year Fixed Effect & Y & Y & Y & Y \\
\hline Industry Fixed Effects & Y & Y & Y & $\mathrm{Y}$ \\
\hline $\begin{array}{l}\text { Controls: Household and } \\
\text { Policy }\end{array}$ & Y & Y & Y & Y \\
\hline Clustered SEs? & Y & Y & Y & Y \\
\hline ACS Sample Weights? & Y & Y & Y & Y \\
\hline
\end{tabular}

This table focuses on extremely high income households who are likely to be most sensitive to tax differentials. The sub-focus is to compare recent movers from people living in their house for a long time. Column (1) are the sub-sample of households who moved into their house within the last year. Column (2) are households who moved in the last two years. Columns (3) and (4) are households who last moved over ten and twenty years ago. The dependent variable is the household commute time, the variable $R$ is one when the CBSA has a reciprocity agreement in place, $m t r$ is the marginal tax rate paid, and $\triangle a t r$ is the average tax rate in the state of residence minus the counter-factual average tax rate. All standard errors are clustered at the CBSA level. $* * * 99 \%,{ }^{* *} 95 \%$, and ${ }^{*} 90 \%$. 
in a more non-parametric way than if we included the actual tax differential. The results are presented in table A.4. It is hard to compare the magnitudes of the coefficients across the tables, but a simple comparison using the average differentials indicates that the dummy variable approach intensifies the size of the effects in absolute value (especially in reciprocity states), but the signs of the effects are preserved. In the same table, instead of using a person specific measure of the tax differential we also show the results using the aggregated differential across all households in the MSA in a given year. This would be appropriate if households responded to the tax systems differentials as if they applied to the average person. We also show results where we restrict the set of CBSAs used to ones where the areas cross only two state borders. 


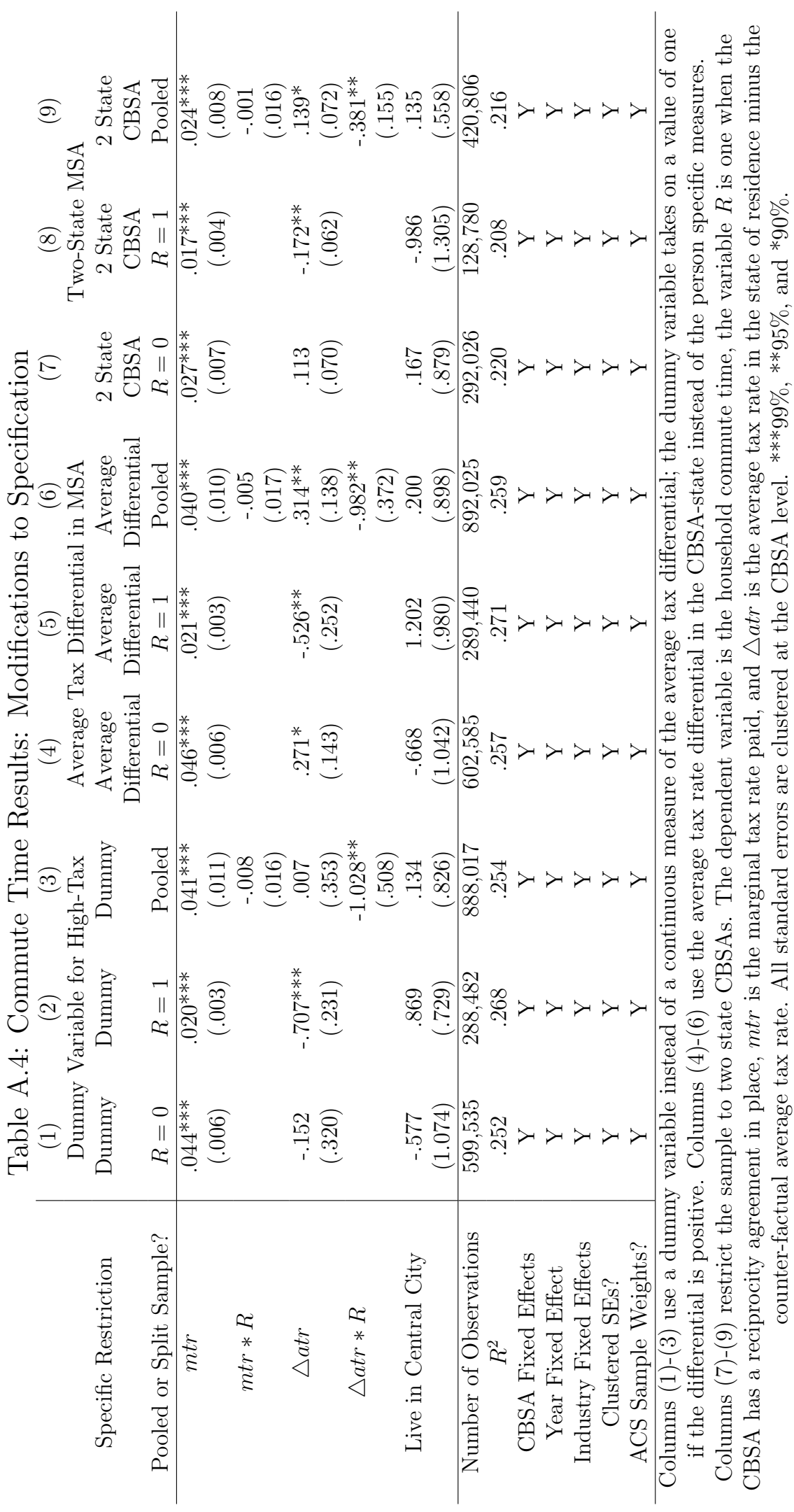

